\title{
Belgian consensus guideline on the management of hemorrhoidal disease
}

\author{
H. De Schepper ${ }^{1}$, G. Coremans², M.A. Denis ${ }^{3}$, P. Dewint ${ }^{1,4}$, M. Duinslaeger ${ }^{5}$, I. Gijsen ${ }^{6}$, P. Haers ${ }^{7}$, N. Komen ${ }^{8}$, C. Remue ${ }^{9}$, \\ P. Roelandt ${ }^{2}$, M. Somers ${ }^{1}$, M. Surmont ${ }^{10}$, D. Van de Putte ${ }^{11}$, S. Van den Broeck ${ }^{8}$, C. Van Kemseke ${ }^{12}$, D. De Looze ${ }^{13}$ \\ (1) Department of Gastroenterology \& Hepatology, University Hospital Antwerp, Belgium ; (2) Department of Gastroenterology and Hepatology, University Hospitals \\ Leuven, Leuven, Belgium ; (3) Department of Gastroenterology \& Hepatology, Cliniques Universitaires Saint-Luc, Brussels, Belgium ; (4) Department of Gastroenterology \\ and Hepatology, Maria Middelares Hospital, Ghent, Belgium ; (5) Department of Abdominal Surgery, University Hospital Brussels, Brussels, Belgium ; (6) Department of \\ Gastroenterology and Hepatology, Noorderhart Hospital, Overpelt, Belgium ; (7) Department of Abdominal Surgery, Heilig Hart Leuven Hospital, Leuven, Belgium ; (8) \\ Department of Abdominal Surgery, University Hospital Antwerp, Antwerp, Belgium ; (9) Colorectal Surgery Unit, Cliniques Universitaires Saint-Luc, Brussels, Belgium ; \\ (10) Department of Gastroenterology and Hepatology, University Hospital Brussels, Brussels, Belgium ; (11) Department of Abdominal Surgery, University Hospital Ghent, \\ Ghent, Belgium ; (12) Department of Gastroenterology and Hepatology, University Hospital Liege, Liege, Belgium ; (13) Department of Gastroenterology and Hepatology,
} University Hospital Ghent, Ghent, Belgium.

\begin{abstract}
Introduction : Hemorrhoidal disease is a common problem that arises when hemorrhoidal structures become engorged and/or prolapse through the anal canal. Both conservative and invasive treatment options are diverse and guidance to their implementation is lacking.

Methods: A Delphi consensus process was used to review current literature and draft relevant statements. These were reconciliated until sufficient agreement was reached. The grade of evidence was determined. These guidelines were based on the published literature up to June 2020.

Results: Hemorrhoids are normal structures within the anorectal region. When they become engorged or slide down the anal canal, symptoms can arise. Every treatment for symptomatic hemorrhoids should be tailored to patient profile and expectations. For low-grade hemorrhoids, conservative treatment should consist of fiber supplements and can include a short course of venotropics. Instrumental treatment can be added case by case : infrared coagulation or rubber band ligation when prolapse is more prominent. For prolapsing hemorrhoids, surgery can be indicated for refractory cases. Conventional hemorrhoidectomy is the most efficacious intervention for all grades of hemorrhoids and is the only choice for non-reducible prolapsing hemorrhoids.

Conclusions : The current guidelines for the management of hemorrhoidal disease include recommendations for the clinical evaluation of hemorrhoidal disorders, and their conservative, instrumental and surgical management. (Acta gastroenterol. belg., 2021, 84, 101-120).
\end{abstract}

Keywords : hemorrhoidal disease, internal hemorrhoids, external hemorrhoids, bleeding, prolapse, thrombosis.

Abbreviations : $\mathrm{CH}$ : conventional hemorrhoidectomy ; DGHAL : Doppler-guided hemorrhoidal artery ligation ; IBD : inflammatory bowel disease ; IR : infrared ; MPFF : micronized purified flavonoid fraction; RAR : recto-anal repair; RBL : rubber band ligation; RCT : randomized controlled trial; RFA : radiofrequency ablation; $\mathrm{SH}$ : stapled hemorrhoidopexy.

\section{Introduction}

Internal hemorrhoids are normal anatomical structures which play a role in maintaining anal continence. When they become engorged or protrude through the anal canal, they can cause of bothersome complaints, a condition referred to as symptomatic hemorrhoids or hemorrhoidal disease. There are multiple conservative and surgical treatment options to manage symptomatic hemorrhoids, but guidelines are limited and often unequivocal. The purpose of this manuscript is to provide an evidence- based consensus review on the practical management of hemorrhoidal disease. In addition, several newer treatment options will be critically reviewed.

\section{Methods}

The Belgian Working Group on Proctology initiated a Delphi process, to develop consensus statements for the management of hemorrhoidal disease in clinical practice. The Delphi approach, which combines the principles of evidence-based medicine, supported by systematic literature reviews and a voting process, aims at determining consensus for complex problems in medicine for which evidence from controlled trials is lacking (1).

The principal steps in the process were : 1) selection of a Working Group of 5 proctologists (both surgeons and gastroenterologists) with expertise in management of hemorrhoidal disease ; 2) selection of a national Consensus Group consisting of experts in proctology ; 3) drafting of statements allowing to evaluate the current knowledge on management of hemorrhoidal disease; 4) systematic literature reviews to identify evidence to support each statement ; 5) three rounds of repeated voting of the statements until a stable level of consensus was reached; and 6) grading of the strength using accepted criteria.

We conducted a systematic literature search using relevant keywords (MeSH : hemorrhoids, conservative treatment, surgical treatment, etc). The 5 Working Group members drafted a list of topics which were distributed among the Consensus Group members for critical literature review. Several relevant statements were deduced by the Working Group and distributed among the Consensus group members for voting and review. After a first voting round by all members, a consensus meeting was organized where all statements were

Correspondence to : Heiko De Schepper, MD PhD, Department of Gastroenterology \& Hepatology, University Hospital Antwerp, Drie Eikenstraat 655, 2650 Edegem, Belgium. Phone : +32 38215585.

Email : Heiko.DeSchepper@uza.be

Submission date : 14/09/2020

Acceptance date : 14/10/2020 
extensively discussed and reconciled where necessary and possible. Next, the 5-member Working Group drafted a revised list of statements which was again distributed for voting. For each voting round, each statement was presented with the evidence summary, and then the entire panel indicated the degree of agreement for the statement using a 6-point Likert scale (Table 1). When $80 \%$ of the Consensus Group agreed $(\mathrm{A}+$ or $\mathrm{A})$ with a statement, this was defined as consensus and included in the formal guideline document. All votes were mutually anonymous. The strength of evidence for each statement was scored using the GRADE system (Table 2) (2). All statements that reached consensus are grouped in table 3 .

\section{Pathophysiology and clinical characteristics}

\section{a) Anatomy (figure 1)}

Hemorrhoids are clusters of vascular tissues (arterioles, venules and direct shunts or communication between them giving rise to formation of vascular sinusoids), smooth muscle and connective tissue which classically form three cushions located along the anal canal in left-lateral, right-anterior and right-posterior position and represent normal structures of the human body. According to the position of the hemorrhoidal plexus relative to the dentate line, hemorrhoids are classified as internal or external (3).

External hemorrhoids: External hemorrhoids are located distally to the dentate line and originate from ectoderm embryonically. They are covered by squamous epithelium of the anoderm and innervated by nociceptive somatic fibers supplying the perianal skin. External hemorrhoids receive blood from the inferior rectal artery. Venous outflows are via the inferior rectal veins into the pudendal vessels and then into the internal iliac veins. Because they are functionally and anatomically quite distinct from internal hemorrhoids, external hemorrhoids are often referred to as perianal veins in textbooks and literature.

Internal hemorrhoids: Internal hemorrhoids are located proximally to the dentate line in the anal canal, which derives from endoderm (muscles and vessels derive from mesoderm). They are covered by transitional columnar epithelium and are innervated by visceral nerve fibers (which are incapable of somatic nociception). The internal hemorrhoidal plexus receives blood from the superior and the middle rectal arteries. Venous outflow is directed to the three rectal veins (superior, middle and inferior), predominantly the superior and the middle

Table 1. - 6-Point Likert scale to indicate agreement

\begin{tabular}{|l|l|}
\hline A + & strongly agree \\
\hline A & mostly agree \\
\hline A- & somewhat agree \\
\hline D- & somewhat disagree \\
\hline D & mostly disagree \\
\hline D + & strongly disagree \\
\hline
\end{tabular}

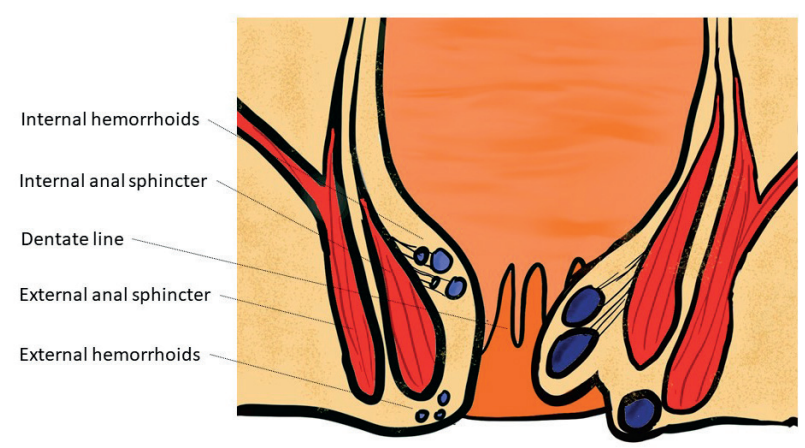

Figure 1. - Anatomy of the anal canal including internal and external hemorrhoids. On the right side of the figure, potential mechanisms of hemorrhoidal disease are shown : engorgement, prolapse and thrombosis.

rectal veins. The superior rectal vein drains into the inferior mesenteric vein belonging to the portal venous circulation, while the middle and the inferior rectal veins belong to the systemic circulation via the internal iliac vein.

The fixation of the anal cushions above the dentate line and the prevention of their prolapse are ensured by 1) the Park's ligament, fixing the cushions to the internal anal sphincter and to the conjoined longitudinal muscle ; 2) the integrity of the connective tissue located between the sinusoids ; 3) the sphincter-like structure in the terminal arterioles and the small caliber of the terminal branches of the supplying arteries that prevent hyperperfusion of the sinusoids (4).

Hemorrhoidal cushions contribute to $15-20 \%$ of anal canal resting tone and continence (5). Their volumeoccupying effect seals the anal canal at rest and prevents fecal soiling. During defecation the anal cushions slide down and their size reduces due to 1) the increased venous drainage which is favored by the relaxation of the internal anal sphincter, 2) the dilation of the anal canal by descending stool and 3) the contraction of the cushions by the Park's ligament. After defecation the anal cushions return upwards to their usual position and rapidly fill with blood until they reach their usual size (3).

Table 2. - Grade system used to score the strength of evidence (1)

\begin{tabular}{|l|l|}
\hline High (A) & $\begin{array}{l}\text { We are very confident that the true effect lies close } \\
\text { to that of the estimate of the effect }\end{array}$ \\
\hline Moderate (B) & $\begin{array}{l}\text { We are moderately confident in the effect estimate: } \\
\text { The true effect is likely to be close to the estimate } \\
\text { of the effect, but there is a possibility that it is } \\
\text { substantially different }\end{array}$ \\
\hline Low (C) & $\begin{array}{l}\text { Our confidence in the effect estimate is limited: } \\
\text { The true effect may be substantially different from } \\
\text { the estimate of the effect }\end{array}$ \\
\hline Very low (D) & $\begin{array}{l}\text { We have very little confidence in the effect } \\
\text { estimate: The true effect is likely to be substantially } \\
\text { different from the estimate of effect }\end{array}$ \\
\hline
\end{tabular}

2. Balshem H, Helfand M, Schunemann HJ, Oxman AD, Kunz R, Brozek J, et al. GRADE guidelines : 3 . Rating the quality of evidence. J Clin Epidemiol. 2011;64(4):401-6. 
Table 3.

\begin{tabular}{|c|c|c|}
\hline STATEMENT & AGREEMENT & GRADE \\
\hline $\begin{array}{l}\text { 1.1: The most important risk factors to develop hemorrhoidal disease are straining, constipation, diarrhea, } \\
\text { pregnancy and obesity. }\end{array}$ & $100 \%$ & $\mathrm{C}$ \\
\hline $\begin{array}{l}\text { 1.2: A total colonoscopy must be considered (if not recently performed) to rule out a proximal source of bleeding, } \\
\text { and is strictly indicated for patients over the age of } 45 \text { years or with risk factors of colorectal cancer, in case of } \\
\text { anemia, weight loss, change in bowel habit or in absence of response to initial therapy. }\end{array}$ & $100 \%$ & A \\
\hline $\begin{array}{l}\text { 1.3: Only in case of clinical suspicion, inflammatory bowel disease should also be excluded (by fecal calprotectin } \\
\text { or colonoscopy). }\end{array}$ & $100 \%$ & B \\
\hline 1.4: Bleeding and sensation of prolapse are the cardinal symptoms of internal hemorrhoidal disease. & $100 \%$ & A \\
\hline 2.1: Every treatment for symptomatic hemorrhoids should be tailored to patient profile and expectations. & $100 \%$ & $\mathrm{D}$ \\
\hline 3.1: Fiber therapy improves hemorrhoidal symptoms and bleeding in grade I-II hemorrhoids. & $85 \%$ & A \\
\hline 3.2: Topical treatment has no proven effect in the treatment of hemorrhoidal disease. & $92 \%$ & B \\
\hline 3.3: Venotropics can have an effect on bleeding in symptomatic hemorrhoids. & $83 \%$ & A \\
\hline $\begin{array}{l}\text { 3.4: There is no rationale for long-term treatments with venotropics; their use is recommended in acute } \\
\text { hemorrhoidal disease for a short period. }\end{array}$ & $92 \%$ & $\mathrm{D}$ \\
\hline 3.5: Venotropics have no proven effect on hemorrhoidal thrombosis and should not be used for this indication. & $92 \%$ & B \\
\hline $\begin{array}{l}\text { 4.1: IR coagulation is indicated in grade } 1 \text { or } 2 \text { symptomatic hemorrhoids not responding to conservative } \\
\text { treatment. }\end{array}$ & $100 \%$ & A \\
\hline $\begin{array}{l}\text { 4.2: Sclerosing injections can cause severe adverse events, are not superior to IR coagulation and should } \\
\text { therefore be avoided. }\end{array}$ & $83 \%$ & B \\
\hline 4.3: Rubber band ligatures should be placed just proximal to the hemorrhoid. & $100 \%$ & $\mathrm{D}$ \\
\hline 4.4: Rubber band ligation can be used for grade 2 to 3 internal hemorrhoids. & $92 \%$ & A \\
\hline 4.5: For grade 2 hemorrhoids, rubber band ligation seems the logical first choice of treatment. & $92 \%$ & A \\
\hline $\begin{array}{l}\text { 5.1: Surgical treatment of hemorrhoids can be proposed after failure of medical and instrumental treatments } \\
\text { (infra-red, sclerosis, elastic band ligations) for grade } 2 \text { and } 3 \text { hemorrhoidal disease. }\end{array}$ & $92 \%$ & A \\
\hline 5.2: Surgery is indicated as first line therapy for grade 4 and large grade 3 hemorrhoids. & $100 \%$ & A \\
\hline 5.3: Surgery is indicated for acute complications (pain/necrosis/thrombosis) if conservative therapy fails. & $92 \%$ & $\mathrm{D}$ \\
\hline $\begin{array}{l}\text { 5.4: Surgery is indicated for hemorrhoidal bleeding resulting in severe and otherwise unexplained anemia, } \\
\text { irrespective of the anatomical stage of disease. }\end{array}$ & $85 \%$ & $\mathrm{D}$ \\
\hline $\begin{array}{l}\text { 5.5: Surgery is indicated for symptomatic internal hemorrhoids that are associated with symptomatic external } \\
\text { hemorrhoidal disease resistant to conservative therapy: recurrent external hemorrhoidal thrombosis resistant to } \\
\text { conservative therapy or bothersome hypertrophic tags. }\end{array}$ & $92 \%$ & $\mathrm{D}$ \\
\hline $\begin{array}{l}\text { 5.6: Surgery is indicated for symptomatic internal hemorrhoids in association with other surgical proctology } \\
\text { disease where conservative therapy fails: anal fissure, condyloma. }\end{array}$ & $100 \%$ & $\mathrm{D}$ \\
\hline 5.7: Conventional hemorrhoidectomy is the gold standard in surgical therapy for grade $3-4$ hemorrhoids. & $100 \%$ & A \\
\hline $\begin{array}{l}\text { 5.8: Compared to rubber band ligation conventional hemorrhoidectomy has a superior long-term efficacy for } \\
\text { grade } 3 \text { hemorrhoids at the cost of more side effects. }\end{array}$ & $100 \%$ & A \\
\hline $\begin{array}{l}\text { 5.9: Conventional hemorrhoidectomy is the preferred procedure for noncircumferential hemorrhoids and in case } \\
\text { of concomitant bothersome external hemorrhoids/skin tags. }\end{array}$ & $92 \%$ & $\mathrm{D}$ \\
\hline $\begin{array}{l}\text { 5.10: Stapled hemorrhoidopexy is associated with less pain and faster recovery compared to conventional } \\
\text { hemorrhoidectomy, but suffers from higher recurrence rates. }\end{array}$ & $100 \%$ & A \\
\hline $\begin{array}{l}\text { 5.11: Doppler-guided hemorrhoidal artery ligation is associated with less complications compared to stapled } \\
\text { hemorrhoidopexy and conventional hemorrhoidectomy. }\end{array}$ & $85 \%$ & A \\
\hline $\begin{array}{l}\text { 5.12: Doppler-guided hemorrhoidal artery ligation has a significantly higher persistence/recurrence rate } \\
\text { compared to stapled hemorrhoidopexy. }\end{array}$ & $92 \%$ & A \\
\hline $\begin{array}{l}\text { 5.13: Stapled hemorrhoidopexy and Doppler-guided hemorrhoidal artery ligation are not recommended in cases } \\
\text { of grade } 4 \text { hemorrhoidal disease. }\end{array}$ & $100 \%$ & B \\
\hline $\begin{array}{l}\text { 6.1: During pregnancy, conservative options are treatment of choice and hemorrhoidal disease should be } \\
\text { reevaluated after delivery. }\end{array}$ & $100 \%$ & $\mathrm{C}$ \\
\hline 6.2: Venotropics are probably safe during pregnancy, safety during lactation is unknown. & $100 \%$ & $\mathrm{C}$ \\
\hline 6.3: IR coagulation should be avoided during pregnancy. & $85 \%$ & B \\
\hline 6.4: pregnancy is an absolute contraindication for rubber band ligation. & $92 \%$ & $\mathrm{~B}$ \\
\hline 6.5: IR coagulation should be avoided in active anorectal inflammatory bowel disease. & $100 \%$ & $\mathrm{~B}$ \\
\hline 6.6: Rubber band ligation should be avoided in active anorectal inflammatory bowel disease. & $100 \%$ & $\mathrm{~B}$ \\
\hline $\begin{array}{l}\text { 6.7: If there is clinical suspicion of inflammatory bowel disease, this should be excluded before any type of } \\
\text { proctological surgery. }\end{array}$ & $100 \%$ & B \\
\hline $\begin{array}{l}\text { 6.8: If invasive therapy is needed in inflammatory bowel disease patients, it is advised to perform surgery during } \\
\text { a quiescent phase of the disease. }\end{array}$ & $100 \%$ & B \\
\hline $\begin{array}{l}\text { 6.9: Due to potential complications, specific interventions to treat hemorrhoidal symptoms should be } \\
\text { discouraged after pelvic irradiation, moreover because most of these symptoms are likely to be secondary to } \\
\text { radiation proctopathy rather than hemorrhoids. }\end{array}$ & $100 \%$ & $\mathrm{C}$ \\
\hline $\begin{array}{l}\text { 6.10: There are no contra-indications for any type of treatment for symptomatic hemorrhoids in HIV-positive } \\
\text { patients, depending on CD4 count. }\end{array}$ & $92 \%$ & $\mathrm{C}$ \\
\hline $\begin{array}{l}\text { 6.11: IR coagulation can be safely performed under aspirin and clopidogrel, in all other conditions of disturbed } \\
\text { coagulation it should be used with caution. }\end{array}$ & $61 \%$ & B \\
\hline
\end{tabular}




\begin{tabular}{|c|c|c|}
\hline 6.12: Rubber band ligation should be avoided in patients on clopidogrel. & $92 \%$ & $\mathrm{~B}$ \\
\hline 6.13: Rubber band ligation is contra-indicated in patients on oral anticoagulants. & $85 \%$ & $\mathrm{~B}$ \\
\hline $\begin{array}{l}\text { 6.14: Vitamine } \mathrm{K} \text { antagonists should be stopped for } 7 \text { days, NOACs for } 2 \text { days and antiplatelet agents for } 5 \text { days } \\
\text { before both office-based and surgical interventions. }\end{array}$ & $85 \%$ & B \\
\hline $\begin{array}{l}\text { 6.15: Ideally anticoagulants should be restarted } 2 \text { weeks after rubber band ligation because of an unpredictable } \\
\text { risk of bleeding. After hemorrhoidal surgery, anticoagulants can be restarted immediately because hemostatic } \\
\text { measures are taken during the operations. }\end{array}$ & $100 \%$ & $\mathrm{~B}$ \\
\hline $\begin{array}{l}\text { 6.16: If hemorrhoid treatment is needed under anticoagulant therapy, a one-stage treatment should be preferred } \\
\text { (surgery). }\end{array}$ & $85 \%$ & $\mathrm{~B}$ \\
\hline 6.17: In the immunocompromised patient RBL should be avoided. & $100 \%$ & $\mathrm{C}$ \\
\hline $\begin{array}{l}\text { 6.18: It is advised to postpone elective procedures (office-based or surgical) until the end of adjuvant } \\
\text { chemotherapy or during a drug holiday in case of palliative chemotherapy. }\end{array}$ & $100 \%$ & $\mathrm{D}$ \\
\hline 6.19: Rubber band ligation can safely be performed in compensated liver cirrosis (Child-Pugh A). & $85 \%$ & $\mathrm{C}$ \\
\hline
\end{tabular}

\section{b) Pathophysiology}

Since the hemorrhoidal cushions are physiological structures, it is important to specify when we consider them to be pathologic and a cause of disease. Hemorrhoidal disease refers to a set of symptoms generated by the congestion, thrombosis and/or prolapse of the hemorrhoidal structures. The exact pathophysiology of symptomatic hemorrhoidal disease is not fully understood

Four pathophysiological events are recognized to initiate the disease (3): the sliding process of anal cushions, deterioration of the connective tissue of the cushions, reduction of venous return from the sinusoid to the rectal veins and stagnation of blood inside the dilated and distorted plexus.

\section{c) Epidemiology}

Hemorrhoidal disease is a frequent condition already reported in the Old Testament and in Egyptian, Babylonian and Greek written sources. Although benign, this condition has a high impact on quality of life.

The exact prevalence of hemorrhoidal disease is unknown, most patients who experience benign anorectal symptoms or symptoms compatible with hemorrhoidal disease do not consult a physician and self-treat with over-the-counter therapies (6). In the literature prevalence varies from $4.4 \%$ to $86 \%(7,8)$. Two studies found a similar prevalence of hemorrhoidal disease in a population of participants who underwent a colonoscopy in a colorectal cancer screening program : they reported a $38-39 \%$ prevalence rate of hemorrhoids in their population, $55 \%$ being asymptomatic $(9,10)$. The prevalence seems equal in both genders, with a peak from age 45 to 65 years, development of symptomatic hemorrhoids before age 20 being unusual (8).

\section{d) Risk factors}

Statement 1.1 : The most important risk factors to develop hemorrhoidal disease are straining, constipation, diarrhea, pregnancy and obesity. Agreement 100\%. Grade C.
In literature, numerous risk factors have been studied but conclusions are variable and sometimes contradictory. Conditions that increase intra-abdominal pressure and impair the venous drainage from the hemorrhoidal venous plexus are widely believed to cause symptomatic hemorrhoids : constipation, prolonged straining during defecation, diarrhea, pregnancy and obesity (9-12). Pelvic floor dysfunction, gender, heredity, high socioeconomic status, depression, sedentary behavior, tobacco use, lowfiber diet, spicy food and alcohol intake have also been implicated (10,13-15). Interestingly, patients with portal hypertension and esophageal varices do not seem to have an increased incidence of hemorrhoids (16).

Among these risk factors, constipation (due to the lack of dietetic fibers, among other elements), is traditionally considered as one of the most important. However, several studies have questioned the importance of constipation in the development of hemorrhoidal disease $(13,15,17)$.

\section{e) Clinical and technical investigations}

A complete proctologic examination is imperative for the diagnosis of hemorrhoids (3). The use of clock face terms should be avoided to describe lesions because position of the patient can vary. Instead, physicians should use terms relative to the patient, such as anterior, posterior, left, or right (18). A knee-elbow or pronejackknife position should be preferred to the left-lateral position as the former allows for a more thorough exposition of the anal and perianal structures (expert opinion).

External inspection may reveal thrombosed external hemorrhoids, skin tags or prolapsed internal hemorrhoids. It is important to inspect at rest and during/after straining for the diagnosis of hemorrhoidal prolapse. A digital anorectal examination can detect masses or abscesses and allows for evaluation of sphincteric tone and contractility. Anoscopy will visualize the internal hemorrhoids that look like purplish bulges and can help exclude a distal rectal mass or other conditions mimicking hemorrhoidal disease.

The need for a total colonoscopy to exclude a more proximal source of bleeding should be case-based and depends on risk factor assessment $(19,20)$. 
Statement 1.2 : A total colonoscopy must be considered (if not recently performed) to rule out a proximal source of bleeding, and is strictly indicated for patients over the age of 45 years or with risk factors of colorectal cancer, in case of anemia, weight loss, change in bowel habit or in absence of response to initial therapy. Agreement $\mathbf{1 0 0 \%}$. Grade A.

Statement 1.3 : Only in case of clinical suspicion, inflammatory bowel disease should also be excluded (by fecal calprotectin or colonoscopy). Agreement $100 \%$, Grade $B$.

\section{f) Symptoms}

External hemorrhoids : A painful bluish-colored lump at the anal verge is the main symptom of external hemorrhoidal disease and is due to edema or acute thrombosis. Bleeding can occur if ulceration develops from cutaneous necrosis overlying the thrombosed hemorrhoid. Bleeding from external hemorrhoids is darker and more clotted than the bleeding from internal hemorrhoids (3).

Painless external skin tags often result from previous edematous or thrombosed external hemorrhoids and can facilitate cumbersome anal hygiene after defecation, irritation and pruritus ani.

\section{Internal hemorrhoids}

Statement 1.4 : Bleeding and sensation of prolapse are the cardinal symptoms of internal hemorrhoidal disease. Agreement 100\%. Grade A.

Bleeding is the most common symptom of internal hemorrhoidal disease, usually painless and associated with defecation. The blood is bright red due to its arterial origin, can be found on the toilet paper, coating the stool, or dripping or spraying into the toilet bowl.

The sensation of tissue prolapse is another frequent symptom. It may be accompanied by mild fecal incontinence, mucus discharge, sensation of perianal fullness and irritation of perianal skin.

Pain is less common but can occur in case of complicated internal hemorrhoids : thrombosis, incarceration or strangulation. If no complication of internal hemorrhoids is detected, another etiology of anal pain must be ruled out (perianal abscess, tumor, anal fissure or external thrombosis) $(3,21)$. In particular, an associated anal fissure is a frequent but often missed diagnosis.

\section{Grading}

Hemorrhoidal prolapse can be classified according to its anatomic location as internal (above the dentate line), or external (below the dentate line). A mixed type (internal-external) is described when the prolapse achieves an overlap between internal and external (22).
Internal hemorrhoids are further graded according to their degree of prolapse, as described by Goligher (23) :

- Grade 1 : non-prolapsing hemorrhoids

- Grade 2 : prolapsing hemorrhoids on straining but reducing spontaneously

- Grade 3: prolapsing hemorrhoids requiring manual reduction

- Grade 4 : non-reducible prolapsing hemorrhoids, including acutely thrombosed, incarcerated hemorrhoids.

This grading system focuses exclusively on the prolapse and does not consider the multifactorial and progressive aspect of the hemorrhoidal disease. Other clinical factors such as pain, bleeding, extent of hemorrhoids and patient comorbidities should be taken into account and the Goligher's classification should be considered as a variable and not as a reference element in hemorrhoidal disease classification (24).

Treatment of symptomatic hemorrhoids : general approach

Statement 2.1 : Every treatment for symptomatic hemorrhoids should be tailored to patient profile and expectations. Agreement 100\%. Grade D.

The management of hemorrhoidal disease can be subdivided in conservative treatment, instrumental therapy and surgical interventions. For each possible treatment option, a discussion with the patient should be started detailing the specifics of each treatment and the potential disadvantages or risks related to the treatment. The chosen therapy should always be tailored to patients' expectations.

The majority of what follows applies to internal hemorrhoidal disease. For external hemorrhoids, a separate chapter is added.

\section{Conservative treatment}

\section{a) Life style modification}

First-line therapy for symptomatic hemorrhoids usually involves dietary measures (adequate fluid and fiber intake) along with stool pattern modification (avoiding straining and limiting prolonged time on the toilet and use of a footstool). There is no scientific evidence to defend these rather general measures which are purely based upon expert opinion. There is equally no literature on the effect of alcohol or coffee consumption. There is one randomized controlled trial studying the effect of adding chili powder to the diet of patients suffering from hemorrhoidal disease, showing no difference in symptom severity compared to placebo, so the advice to avoid spicy food is also of little value (25). 


\section{b) Stool pattern modification : fiber therapy}

Statement 3.1: Fiber supplementation improves hemorrhoidal symptoms and bleeding in grade 1-2 hemorrhoids. Agreement 85\%. Grade A.

Both diarrhea and constipation are associated with the development of hemorrhoidal disease. Normalizing stool pattern can improve symptoms, mainly bleeding. Especially the use of fiber has a beneficial effect in hemorrhoidal disease, as fiber supplementation can improve both constipation and diarrhea. In addition, this intervention is safe (most common side effect is mild to moderate bloating) and cheap. A Cochrane systematic review showed that risk of symptoms and risk of bleeding were significantly lower in the fiber-treated group compared to placebo $(\mathrm{RR}=0.53,95 \% \mathrm{CI} 0.38$ 0.73 for persisting symptoms and $\mathrm{RR}=0.50,95 \% \mathrm{CI}$ 0.28-0.89 for bleeding) $(26,27)$. There are no data on the use of osmotic or other laxatives on the evolution of symptomatic hemorrhoidal disease. Still, clinical practice suggests that these products are useful and efficacious in patients with symptomatic hemorrhoids and constipation when fibers are not tolerated (expert opinion).

\section{c) Stool pattern modification : pelvic floor re-education}

Avoiding of straining on defecation was shown to limit the prolapse of hemorrhoids $(28,29)$. Currently there are no data concerning the effect of biofeedback therapy on recurrence of hemorrhoids. The goals of biofeedback therapy are to educate patients about disordered defecation, coordinate increased intraabdominal pressure with pelvic floor muscle relaxation during evacuation, and practice simulated defecation with a balloon, aided by a therapist (30). Biofeedback therapy improves the number of complete spontaneous bowel movements per week in patients with dyssynergic defecation, and prevents excessive straining (30). Hence, one might expect this modality to have a positive effect on hemorrhoidal disease as well in this specific population. Nonetheless, specific studies confirming this hypothesis are not available.

\section{d) Topical treatment}

STATEMENT 3.2 : Topical treatment has no proven effect in the treatment of hemorrhoidal disease Agree-ment 92\%. Grade B.

There are several topical formula available for the treatment of symptomatic hemorrhoids: creams, ointments and suppositories. These are over-the-counter products which are broadly used in primary care, and even in secondary centers, even though the evidence base for their use is virtually non-existent. As they are often prescribed unnecessarily (for any often poorly diagnosed anal problem and for too long) these products represent a major health cost (31). As there are no studies available demonstrating benefit of these products over placebo or other treatment modalities, their use cannot be defended.

Topical preparations to treat hemorrhoidal disease typically contain varying doses of lubricants, mucoprotectants, local anesthetics (lidocaine, cinchocaine), sclerosing agents (polidocanol) and/or corticosteroids (triamcinolone, prednisolone). Intuitively, they can have a role in the treatment of acute manifestations of external hemorrhoidal disease with active inflammation, pain and congestion, although this is mainly expert opinion. Preparations containing corticosteroids should only be used for short treatment courses (maximum 14 days) to avoid evolution to skin atrophy, sensitization and allergic reactions.

There may be a place for topical treatment of pain after surgery for hemorrhoidal disease. Some agents containing a nitrate donor or a calcium channel blocker may help to relax the internal anal sphincter, reduce congestion of hemorrhoids and alleviate pain intensity (32).

e) Venotropics

Statement 3.3 : Venotropics can have an effect on bleeding in symptomatic hemorrhoids. Agreement $83 \%$. Grade A.

Statement 3.4: There is no rationale for longterm treatments with venotropics; their use is recommended in acute hemorrhoidal bleeding for a short period. Agreement $92 \%$. Grade D.

Statement 3.5 : Venotropics have no proven effect on hemorrhoidal thrombosis and should not be used for this indication. Agreement 92\%. Grade B.

Venotropics are frequently used as part of conservative treatment in symptomatic hemorrhoidal disease. This is a heterogenous class of drugs containing plant extracts and synthetic compounds, such as flavonoids. Most clinical trials evaluating venotropics in patients with hemorrhoids are published on the use of flavonoids, including diosmin, hidrosmin, hesperidin and (hydroxyethyl-) rutosides. Micronised purified flavonoid fraction (MPFF) is the most popular and researched flavonoid in clinical practice.

These agents claim to improve venous tone, stabilize capillary permeability and increase lymphatic drainage. The postulated mode of action is based on vascular pathophysiology, but the true mechanism remains unclear.

A Cochrane review in 2012 evaluated all types of venotropics in different kinds of symptomatic hemorrhoidal disease (33). A total of 2344 participants in 
20 controlled trials were enrolled. The most commonly used agent was MPFF, next to diosmin. Venotropics demonstrated a statistically significant beneficial effect for the outcome of pruritus (OR 0.23), bleeding (OR 0.12), bleeding post-hemorrhoidectomy (OR 0.18), discharge and leakage (OR 0.12) and overall symptom improvement (OR 0.16) in comparison with a control intervention. They did not show a statistically significant effect for pain, pain score post-hemorrhoidectomy or post-operative analgesic consumption.

The meta-analysis by Alonso-Coello et al. in 2006 examined the efficacy of all types of flavonoids (34). They included 14 parallel-group randomized trials (1514 patients) comparing a flavonoid versus placebo. They found a statistically significant benefit of flavonoids in hemorrhoidal disease, with a reduction in the risk of bleeding by $67 \%$, of persistent pain by $65 \%$, of pruritus by $35 \%$ and reduction of relapse by $47 \%$. The risk of not improving or having persisting symptoms decreased by $58 \%$ with flavonoids.

The systematic review by Aziz et al. in 2018 showed a significant difference in bleeding risk, favoring the MPFF group (35). Ten randomized controlled trials involving 1164 participants were included. On the other hand, there was no statistically significant benefit associated with MPFF when compared to placebo for the outcomes of pain relief, pruritus and overall symptom improvements.

The methodological quality of the studies in these 3 meta-analyses ranges from poor to moderate due to unclear risks of bias, poor reporting of trials and heterogeneity of the included studies. This highlights the need for further, more rigorous research in order to enhance conclusions in the future.

There is no rationale for long-term treatments with venotropics; their use can be recommended in symptomatic hemorrhoidal disease for a short period although there is no evidence detailing how long this period should be (36).

There are few concerns regarding the overall safety of venotropics. Mild gastro-intestinal side-effects are reported (33). The meta-analysis of Aziz et al. showed no statistically significant difference in the incidence of adverse events between MPFF and control intervention (35).

To summarize, the use of venotropics can be recommended in symptomatic hemorrhoidal disease for short-term treatments. In general, venotropics have a significant beneficial effect on bleeding, discharge and overall symptom improvement but no effect on pain; where the remark should be made that pain and discharge are not cardinal hemorrhoidal complaints. Data concerning only the use of flavonoids show a reduction in bleeding and pruritus as well. In contrast to common belief, venotropics have no proven effect on hemorrhoidal thrombosis and should not be used for this indication.

\section{Instrumental therapy}

Instrumental treatment is only indicated in symptomatic internal hemorrhoidal disease, i.e. in case of internal hemorrhoidal bleeding or prolapse. There is no indication for these treatments in acute hemorrhoidal thrombosis.

\section{a) Available techniques}

In Belgium 3 techniques are readily available: infrared photocoagulation, sclerosing injections and rubber band ligation. Radiofrequency ablation is a non-reimbursed technique gaining interest in this field balancing between an outpatient instrumental technique and inpatient surgical treatments. Laser coagulation and Emborrhoid therapy can be classified in the same intermediate category.

The 3 mentioned techniques aim at creating a fibrotic reaction at the top of the hemorrhoids, causing a local fixation of the vascular cushion to the underlying muscle and obstruction of the submucosal vascularization. All treatments can be performed on an outpatient basis.

The material used should preferentially be single use. If single use is not possible high-level disinfection (autoclave) must be performed for the ligature device and sclerosing needle, and intermediate level disinfection (cfr. endoscope reprocessing) for the tip of the infrared probe.

\section{b) Infrared (IR) photocoagulation}

Statement 4.1: IR coagulation is indicated in grade 1 or 2 symptomatic hemorrhoids not responding to conservative treatment. Agreement $100 \%$. Grade A.

\section{I) Technique}

Infrared photocoagulation uses infrared light as a thermal source to create a lesion at the top of the hemorrhoid, at least $1 \mathrm{~cm}$ above the dentate line, in the glandular/transitional anal mucosa. There are no studies looking at the ideal number of applications that should be done during one treatment session (variable 3-9; of which 1 or 2 , even 3 above each hemorrhoid). There is no consensus for the duration of the coagulation (11.5 seconds), nor there is any agreement regarding the interval and frequency of treatments.

Arbitrarily, 4-6 points of coagulation are applied. The patients are generally treated until resolution of symptoms, with a maximum of 3 sessions with an interval of 4 weeks (expert opinion).

\section{II) Indication}

Infrared photocoagulation is indicated for the treatment of hemorrhoidal bleeding, with certainty attributable to grade 1 or 2 prolapsing hemorrhoids and not responding to conservative treatment (fiber, stool pattern). If grade 3 
or 4 prolapse is present infrared photocoagulation is not recommended.

\section{III) Efficacy}

Efficacy following infrared photocoagulation is reported in 8 randomized controlled trials, ranging between 75 and $80 \%$ at 1 year following multiple treatment sessions (37-43).

\section{IV) Side effects}

Postprocedural pain following infrared photocoagulation is variable amongst the different studies ranging from $0-100 \%$ (37-46). Severe pain is not mentioned. Postprocedural bleeding is reported in $1.4-44.4 \%$ in the same studies. It is not clear if this means continuous bleeding from the hemorrhoids or procedure-related bleeding. Severe complications such as pelvic sepsis are not reported following infrared photocoagulation.

\section{c) Sclerosing injections}

Statement 4.2: Sclerosing injections can cause severe adverse events, are not superior to IR coagulation and should therefore be avoided. Agreement $83 \%$. Grade B.

\section{I) Technique}

A sclerosing agent is injected in the submucosal layer at the top of the internal hemorrhoid, in the glandular mucosa. Depth of injection is $2-5 \mathrm{~mm}$, more superficial injections cause blanching of the mucosa, too deep injection in the muscularis/anal sphincter can be very painful. Injections at the anterior midline should be avoided because of the risk of injection in the prostate or the rectovaginal septum. It is generally recommended to inject 1-3 $\mathrm{ml}$ at the top of the hemorrhoids. The sclerosing injections can be repeated at 4 weeks interval, maximally 3 treatment sessions. The products that can be used are "quinine urea hydrochloride", "phenol in almond oil" or "polidocanol".

\section{II) Indication}

Sclerosing injections are indicated for the treatment of hemorrhoidal bleeding, with certainty attributable to grade 1 or grade 2 prolapsing hemorrhoids and not responding to conservative treatment (fiber, stool pattern).

\section{III) Efficacy}

No studies are available with quinine urea hydrochloride, which is often used in Belgium and France. All published studies were performed with phenol in almond oil and polidocanol. Short term success is comparable to the other instrumental therapies : $60-70 \%$ after 1 or repeated injections (45-50).

At longer follow-up success rates drop to $30 \%$ at 1 year and $25 \%$ at 3 years (46). More recent randomized trials have been done in very small numbers of patients and show similar symptomatic control (49-51). The most recent prospective trial also showed disappointing longterm results of only $25 \%$ at 26 weeks (50).

\section{IV) Side effects}

There is an important issue with side-effects caused by sclerosing injections (52-64). Although rare, they can be severe and life-threatening.

Mild anal pain is reported in $9-70 \%$ of patients, minor anal bleeding in $2-10 \%(45,46)$. In the published series no severe side-effects were observed, but several case reports were published with sclerotherapy-related abscess or pelvic cellulitis. In $8 \%$ transient bacteremia was observed following sclerosing injection. Erectile dysfunction has been described in 3 patients, following prostate injection and hematospermia.

One should also consider the very low incidence of allergic reaction/anaphylactic shock by the sclerosing agent. For quinine derivatives, allergy is estimated to be around $1 \%$. Allergic reactions to polidocanol are estimated at 1:10000 but may be underestimated.

Because of the potential severe side-effects and the lack of superiority versus infrared photocoagulation and rubber band ligations, we advise to avoid sclerosing injections for the treatment of grade 1 and 2 prolapsing hemorrhoids.

Sclerosing injections are absolutely contra-indicated in pregnancy, inflammatory state of the anal canal and rectum, immunosuppression and coagulation disorders. It can be performed in patients under a low dose of aspirin.

\section{v) Polidocanol foam : Alternative option?}

Polidocanol foam is a mixture of polidocanol $2 \mathrm{ml}$ and air which is injected into the hemorrhoid itself. A single center/single operator series reports a success rate of $62 \%$ after 1 session. $28 \%$ of patients needed a second session and $9 \%$ a third. Patient satisfaction was very high : $98 \%$ (65).

The rationale for this treatment is the higher adhesion capacity of foam to the endothelium and thus a greater sclerosing capacity. No serious side effects are reported.

However, we must remind that in the eighties of the previous century, the intra-hemorrhoidal sclerosing injections were abandoned, in favor of the perihemorrhoidal fixation, because of the risk of anaphylactic shock. Therefore, we cannot advise this treatment for hemorrhoidal disease, although its success in peripheral venous disease is well-established.

d) Rubber band ligation (RBL)

Statement 4.3 : RBL should be placed just proximal to the hemorrhoid. Agreement 100\%. Grade D.

Statement 4.4 : RBL can be used for grade 2 to 3 internal hemorrhoids. Agreement 92\%. Grade A 


\section{Statement 4.5 : For grade 2 hemorrhoids, RBL seems the logical first choice of treatment. Agreement 92\%. Grade A.}

\section{I) Devices}

Most commonly a handheld ligator device is used that allows for application of a rubber band at the top of the hemorrhoid through a rigid proctoscope. This band diminishes the blood supply towards the hemorrhoid but most importantly creates an ulceration after sloughing of the ischemic tissue in the band, which subsequently heals and becomes fibrotic, reducing the mucosal prolapse (66). Band ligation can be performed using suction or forceps. Suction is however significantly less painful and causes less bleeding than forceps (67).

The handheld suction ligator that is used via a rigid proctoscope has some drawbacks : its maneuverability is somewhat limited, and the field of view is rather narrow. With a flexible video-endoscope in retrovision in the rectum, hemorrhoids are nicely exposed, and the dentate line is easily seen. Using a classical banding device (for esophageal varices) multiple ligations can be performed within a single procedure $(68,69)$. This single-use multiband device is however not reimbursed in Belgium for this indication.

\section{II) Technique}

Most important is that the bands are placed at the top of the protruding hemorrhoid. In the literature it is mentioned to place the band from a few millimeters to at least $2 \mathrm{~cm}$ proximal to the dentate line (70). We propose not to measure but to have a thorough look at the anal anatomy and place the band at the top of the hemorrhoid suctioning the mucosa just proximal to it. If the band is placed too low (and thus close to the highly innervated dentate line), patients will experience more postprocedural pain.

Immediate post-procedural pain can be due to banding of the deeper muscle layer causing ischemia of the muscle. The band should be freely mobile if no muscle is trapped and will feel "fixed" if there is muscle caught in the band. To reduce the number of sessions, multiple bands can be placed in one session. This however depends on the technique and size of ligator cup which is used. Using a handheld suction ligator, 1 to 3 bands can be placed (67). Using an endoscope in retroflex up to 6 bands can be placed (69). In most published series an interval of 3-4 weeks between sessions is proposed. If no improvement is seen after 3 treatment sessions, another therapy should be considered.

III) Indication

RBL can be used for grade 2 to 3 internal hemorrhoids.

\section{IV) Efficacy}

RBL has a high success rate reaching more than $90 \%$ at 1 year of follow-up in several randomized controlled trials (see further for comparative results). Several studies have focused on technical aspects.

One RCT of 100 patients found that fewer treatment sessions and fewer bands were required by using endoscopically applied bands compared with ligation via rigid proctoscopy (71). This may be because of the smaller diameter of the conventional ligator $(9 \mathrm{~mm})$ in this study compared with that of the endoscopic multiligator $(11 \mathrm{~mm})$. No significant differences were noted in postligation bleeding, analgesics requirement, or recurrent bleeding at 12 month follow-up.

In a study by Lee et al in 1994, most patients tolerated multiple hemorrhoidal banding in a single session but in the group that was treated with more than 1 band, there were more vasovagal symptoms, more edema and more urinary hesitancy (72). A recent cohort study with endoscopic rubber band ligation couldn't show a significant difference in complications between patients who had 1-2 bands, compared to those that were treated with 3 or more band ligations in the same procedure (69) More studies are needed to elucidate these contradictory findings. At this moment, the working group advices not to place more than 2 bands if the classical suction ligation device through a proctoscope is used (expert opinion).

\section{v) Side effects}

Mild bleeding, pain, vasovagal symptoms, priapism, urinary hesitation, anal fissure and chronic longitudinal ulcers are considered minor complications that are not rare following RBL. Major complications are rarely reported and primarily as case reports : massive bleeding, thrombosed hemorrhoids, severe pain, urinary retention requiring catheterization, pelvic sepsis, anal fistula and death $(73,74)$.

Immediate pain/discomfort is common following RBL, although it only lasts a few hours after the procedure and can be managed with paracetamol only. The risk ranges from $8 \%$ to $80 \%$ in different RCT's (74).

Bleeding occurs most frequently after 5-14 days, due to the sloughing of the ligated mucosa. Postprocedural bleeding is reported in up to $50 \%$ of patients (67), however lower rates are reported in other trials (68). Bleeding needing hospital admission or blood transfusion is rare.

Several (rare) infectious complications have been reported : pelvic sepsis, Fournier's gangrene, liver abscesses, tetanus and bacterial endocarditis $(73,74)$. One of the most serious complications is pelvic sepsis. Suspicion should arise in patients with pain, fever, edema and urinary retention, typically 3-10 days following banding. Early recognition and immediate treatment are essential. First treatment consists of broad-spectrum antibiotics and close follow-up. Prophylactic use of antibiotics to prevent this complication is not indicated. 


\section{e) Comparative efficacy of instrumental treatments}

A 1992 meta-analysis of 5 randomized controlled trials (37, 38, 44, 47, 48) (totaling 863 patients) comparing infrared photocoagulation, sclerosing injections and rubber band ligation, showed similar results at 1 year follow-up between the 3 options (45). The patients treated with infrared photocoagulation however needed more repeated treatments than patients treated with rubber band ligation to obtain the same symptomatic result at 1 year. The latter group however showed a significant higher incidence of post-procedural pain. In this metaanalysis infrared photocoagulation is considered first choice because of the lower number of side-effects : pain is present in $0-8 \%$ following infrared, in $5-60 \%$ following rubber band ligature and in $12-70 \%$ following sclerosing injections (45). Early post-procedural bleeding was observed in $1.5-21 \%, 1.4-15 \%$ and $0-10.5 \%$ following infrared photocoagulation, rubber band ligation and sclerosing injections respectively (45).

Another meta-analysis on all available instrumental treatments in hemorrhoidal disease, analyzed the same 5 RCTs regarding instrumental treatment (46). They came to the same conclusion: comparable efficacy amongst the 3 treatments, but more repeated treatments needed with infrared photocoagulation and sclerosing injections, compared to rubber band ligation (46). Despite the higher risk of pain following ligation, the authors concluded that rubber band ligation should be recommended as initial mode of therapy for grade 1 to 3 hemorrhoids.

Long-term results were published in a nonrandomized but large trial with a 3 year follow-up (75). After 3 years patients treated with rubber band ligation were still asymptomatic in $98 \%$, whilst relapses were observed in only $10 \%$ of patients treated with infrared photocoagulation. Temporary rectal tenesmus was observed in $32 \%$ following rubber band ligation and was not observed after infrared photocoagulation. Mild anal pain was observed in $1 / 3$ of patients in both groups.

A Dutch randomized controlled trial comparing infrared and rubber bands showed similar results for both treatment arms with regard to symptom relief (more than $90 \%$ ), but again a higher number of side effects in the ligation group (39). At 10-month follow-up 1/5 in both groups had symptomatic relapse. Similar results were published in a Brazilian series (40).

A smaller trial compared in a randomized study rubber band ligation with infrared photocoagulation (41). Immediate (within 24h) anal pain requiring painkillers and bleeding was more frequent following ligation but furthermore no more complications were seen in this group and both treatment groups showed similar efficacy and patient satisfaction at a modest follow-up of 6 weeks.

A Cochrane analysis comparing excisional hemorrhoidectomy with rubber banding in grade 3 hemorrhoids showed that RBL is less effective, but causes less complications and less time off work than surgery (76). Very recently a cost-effectiveness study was published showing advantage of RBL over all kinds of surgery in the United States (77).

\section{Radiofrequency ablation}

\section{a) Background}

Radiofrequency ablation (RFA) is a novel treatment for symptomatic grade 2-3 hemorrhoids (78). Experience with this device originates from the treatment of varicose disease of the legs, but nowadays radiofrequency ablation is also used in dysplastic Barrett's esophagus and in local therapy for hepatocellular carcinoma and metastatic liver disease.

Radiofrequency treatment for hemorrhoids is claimed to be faster and less painful than other treatment methods, with a shorter recovery time.

\section{b) Technique}

Radiofrequency ablation for hemorrhoids can be done under local anesthesia with or without sedation. A lubricated proctoscope is inserted into the anus to expose the hemorrhoids. Local anesthetic (1\% lidocaine solution) is injected between the submucosa and the inner muscle layer. A disposable probe is connected to a radiofrequency generator and inserted into the hemorrhoid, or a ball electrode is rolled over the surface of the hemorrhoid. The tissue within the hemorrhoid heats up and the hemorrhoid shrinks. The tissue is cooled down using a cold and wet compress. The hemorrhoids may be treated in several sessions.

Two devices are available : Ellman Dual frequency $4 \mathrm{MHz}$ radiofrequency generator (Ellman International Inc., US) (data used in NICE recommendation) and Rafaelo ${ }^{\circledR}$ by F Care Systems Antwerp, Belgium $(78,79)$.

\section{c) Efficacy Ellman device}

In 2018 a NICE (National Institute for health and Care Excellence UK) recommendation was published, using all published series up to 2016 (78-85). Most trials come from one single center in India and one single center in Italy, therefore patient overlap amongst studies is very well possible. If only considering the 5 small randomized controlled trials in grade 2 hemorrhoids, symptom control is achieved after 1 year in $67-92 \%$ of patients for bleeding. Only 1 study was performed in grade 3 hemorrhoids (84).

The NICE recommendation states that the efficacy and safety of RFA therapy for the treatment of grade 1 to 3 hemorrhoids was adequate to support the use of this procedure, on the condition that patients are informed about other treatment options (including non-surgical) for lower grade hemorrhoids, about the possible need for repeat procedures, and about the risk that the procedure can be painful. 


\section{d) Efficacy Rafaelo ${ }^{\circledR}$ device}

Up to now no randomized controlled trials have been published with the Rafaelo ${ }^{\circledR}$ device. The only published data concern the initial German trial in 102 patients with grade 3 hemorrhoids. After 3 months of follow-up good symptomatic relief following RFA was obtained (78). No severe complications were observed, and it was concluded to be a "safe and effective" treatment.

A French case series was presented at the JFHOD 2019 meeting : Didelot et al reported about 42 patients treated with the Rafaelo ${ }^{\circledR}$ device, $1 / 2$ suffering from grade 3 hemorrhoids and 1/3 from grade 4 hemorrhoids (79). At follow-up of 15 months there was a significant decrease in bleeding and prolapse, but in only $62 \%$ bleeding stopped completely and prolapse had disappeared completely in only 9/42 patients. Quality of life was also significantly better and there was a high patient satisfaction with this outpatient therapy.

\section{e) Side effects}

In the larger case series with the Ellman device (up to 240 patients), the following side-effects were described : early bleeding in $10 \%$, heavy bleeding in $1.7 \%$, anal pain in $12 \%$ and anal foul smelling discharge in $2-16 \%(86)$.

\section{f) Conclusion}

We consider it too early to promote this treatment for general use in daily practice and plea for dedicated research with this tool. It is important to warn patients that post-procedural pain may be present.

\section{Laser therapy}

\section{a) Technique}

Intrahemorrhoidal laser coagulation or laser hemorrhoidoplasty was first described in 2009. This technique is performed using a diode laser of 980-1470 $\mathrm{nm}$ wavelength. The perianal skin immediately aboral to the hemorrhoid is penetrated using needle tip cautery. A laser fiber is introduced into the opening until the level of the hemorrhoidal pedicle and coagulation is activated. A maximum of $250 \mathrm{~J}$ is delivered per hemorrhoidal quadrant over five laser pulses with a power of $13 \mathrm{~W}$.

\section{b) Indication}

The technique can be used for grade 2-3 hemorrhoids but is not suitable for grade 4 hemorrhoids. The exact role of this technique compared to other less cumbersome instrumental techniques and more established surgical techniques remains to be determined.

\section{c) Efficacy}

Two randomized controlled trials compared laser hemorrhoidoplasty with hemorrhoidectomy in patients with grade 2-3 hemorrhoids. Laser coagulation resulted in a higher recurrence rate compared to conventional hemorrhoidectomy (especially for prolapse complaints) and less symptom-free patients after one year (87). A different study showed comparable efficacy and recurrence rate compared to Milligan-Morgan resection after one year (88). In both studies, the procedure caused significantly less pain and shorter duration of hospitalization compared to hemorrhoidectomy, but costed significantly more.

\section{d) Side-effects}

Side-effects of laser hemorrhoidoplasty are generally mild due to the minimally invasive nature of the procedure and consist of very mild, transient pain and post-defecatory bleeding (89).

\section{Emborrhoid therapy}

\section{a) Background}

The Emborrhoid technique was first described by Vidal et al in three patients (90). It consists of selective coil embolization of superior rectal arteries to treat symptomatic hemorrhoidal disease. The potential advantages of endovascular access are the selectivity of the embolization and the absence of direct anorectal trauma.

\section{b) Technique}

The Emborrhoid technique is realized under local anesthesia, in the angiography room, via a 5 Fr right femoral artery puncture in daycare patients. 2-3 mm micro-coils are delivered through a microcatheter inserted into the inferior mesenteric artery, as distally as possible to occlude the distal branches of superior rectal arteries.

\section{c) Efficacy}

A first retrospective open cohort study was published on 14 patients ineligible for surgery ( 7 with previous proctological surgery and 10 with coagulation disorders, anticoagulants or cirrhosis) (91). Technical success was good (100\%) with 2 patients requiring additional embolization of posterior rectal arteries. Clinical success at one month was $72 \%$. Only one patient experienced a temporary painful and edematous perianal reaction. A second retrospective multi-centre open cohort study described Emborrhoid in 30 patients ineligible for surgery (92). Clinical success on bleeding was $72 \%$ after one (17 patients) or two embolization sessions (4 patients) after a 5 months median follow-up. Severity of prolapse was not modified.

A prospective study on 25 consecutive patients with grade 2-3 hemorrhoids refractory to medical treatment with a follow-up of 12 months showed technical 
success in $96 \%$ (93). No patient experienced early or late complications. Symptomatic improvement rate and patient's satisfaction rate was $72 \%$ at 12 months. In a 40-patients prospective study, Zakharchenko et al developed a slightly different technique using nonlysing synthetic polyvinyl alcohol (PVA) particles followed by embolization with metallic coils (80). This allowed a more distal embolization at the level of the hemorrhoidal plexus. Despite potential ischemic risk, no immediate complication nor anal pain syndrome was observed. Patient satisfaction was observed in $83 \%$ patients with grade 3 hemorrhoids and $94 \%$ with grade 1-2 hemorrhoids.

\section{d) Conclusion}

The Emborrhoid technique shows promising preliminary results and seems a safe procedure. Current limitations are small sample size, uncontrolled studies, no comparative studies and limited follow-up.

Patients who recur after surgery, who are ineligible for surgery or who are under antiplatelet/anticoagulation therapy or with coagulation disorders could be interesting candidates for this technique. A randomized comparative evaluation with Doppler-guided hemorrhoidal artery ligation (DGHAL) would help to define the role of Emborrhoid technique as a minimally invasive therapeutic alternative.

\section{Surgical therapy}

Statement 5.1 : Surgical treatment of hemorrhoids can be proposed after failure of medical and instrumental treatments (infra-red photocoagulation, sclerosing injections, rubber band ligations) for grade 2 and 3 hemorrhoidal disease. Agreement 92\%. Grade A.

Statement 5.2: Surgery is indicated as first line therapy for grade 4 and large grade 3 hemorrhoids. Agreement 100\%. Grade A.

Statement 5.3: Surgery is indicated for acute hemorrhoidal complications (pain/necrosis/thrombosis) if conservative therapy fails. Agreement $92 \%$. Grade D.

Statement 5.4 : Surgery is indicated for hemorrhoidal bleeding resulting in severe and otherwise unexplained anemia, irrespective of the anatomical stage of disease. Agreement 85\%. Grade D.

Statement 5.5 : Surgery is indicated for symptomatic internal hemorrhoids that are associated with symptomatic external hemorrhoidal disease resistant to conservative therapy: recurrent external hemorrhoidal thrombosis or bothersome hypertrophic tags. Agreement 92\%. Grade D.
Statement 5.6 : Surgery is indicated for symptomatic internal hemorrhoids in association with another proctological disease where conservative therapy fails : anal fissure, condyloma. Agreement $100 \%$. Grade D.

\section{a) Conventional hemorrhoidectomy (CH)}

Statement 5.7: Conventional hemorrhoidectomy $(\mathrm{CH})$ is the gold standard in surgical therapy for grade 3-4 hemorrhoids. Agreement 100\%. Grade A.

Statement 5.8 : Compared to rubber band ligation (RBL), conventional hemorrhoidectomy has a superior long-term efficacy for grade 3 hemorrhoids at the cost of more side effects. Agreement $100 \%$. Grade A.

Statement 5.9: Conventional hemorrhoidectomy is the preferred procedure for noncircumferential hemorrhoids and in case of concomitant bothersome external hemorrhoids/skin tags. Agreement 92\%. Grade D.

I) Milligan-Morgan vs Ferguson

During conventional hemorrhoidectomy $(\mathrm{CH})$, the hemorrhoid is cut from the anoderm and underlying sphincter complex. The best-known techniques are the open hemorrhoidectomy (Milligan-Morgan procedure) and the closed hemorrhoidectomy (Ferguson procedure).

In the Milligan-Morgan procedure, a V-shaped incision is made by the scalpel in the skin around the base of the hemorrhoid, followed by sharp dissection in the submucous space to strip the entire hemorrhoid from its bed. The dissection is carried cranially to the vascular pedicle, which is ligated, and the distal part excised. Classically, the 3 hemorrhoidal pillars are similarly treated, leaving a mucosal bridge in-between to avoid stenosis. The wound is left open and a hemostatic gauze pad is left in the anal canal. The procedure is performed under general or epidural anesthesia. Postoperative pain and acute urine retention are common complications.

The Ferguson hemorrhoidectomy is similar to the Milligan-Morgan method with one difference, being the total or partial closure of the incisions. Postoperative pain, length of hospital stay, post-operative complications, recurrence and risk of surgical site infection were similar to the Milligan-Morgan technique $(94,95)$. Recurrence rates were similar.

Compared to $\mathrm{RBL}, \mathrm{CH}$ has a superior long-term efficacy for grade 3 hemorrhoids, at the expense of more pain, a higher complication rate and longer leave of work. The patients' acceptance is similar for both techniques suggesting that a group of patients prefers complete long-term cure of symptoms with less concern for minor complications (76).

Both RBL and conventional hemorrhoidectomy are options which should be discussed with patients in case 
of grade 3 hemorrhoids, since both techniques have advantages and not all patients have similar expectations of a treatment.

II) Conventional hemorrhoidectomy with Ligasure $\mathbb{R}$

The major drawback of $\mathrm{CH}$ is postoperative pain. With the use of a bipolar energy device (Ligasure $\left.{ }^{\circledR}\right)$, vascular structures up to $7 \mathrm{~mm}$ can be sealed with minimal thermal damage, potentially leading to less postoperative pain (96). Therefore, a modified conventional hemorrhoidectomy was introduced, using the Ligasure $\AA$. A systematic review of randomized controlled trials comparing conventional $\mathrm{CH}$ to $\mathrm{CH}$ performed with the Ligasure ${ }^{\circledR}$ device showed superiority of the latter technique in terms of postoperative pain until postoperative day 14, without adverse effects on complication rate, hospital stay and incontinence rate (97). Recurrence rates seem to be in favor of $\mathrm{CH}$ performed with Ligasure $\AA$, however due to small sample size and short follow up the evidence is insufficient (97). A more recent retrospective analysis showed no difference in recurrence (98).

$\mathrm{CH}$ with Ligasure ${ }^{\circledR}$ was studied more extensively than with other energy devices. The Harmonic ${ }^{\circledR}$ scalpel was compared to Ligasure ${ }^{\circledR}$ for treatment of grade 3 and 4 hemorrhoids in a randomized controlled trial. The Ligasure ${ }^{\circledR}$ appeared to be favorable in terms of postoperative pain. Patient satisfaction, complication and recurrence rates were similar for both groups (99). Another RCT has compared Ligasure ${ }^{\circledR}$ to a tissue welding device (Starion $\AA$ ) that has the potential to improve patient outcomes due to less heat production during the procedure. The authors concluded both techniques to be equivalent (100).

Despite a few well performed RCTs the body of evidence supporting one energy device over the other is insufficient. Therefore, no recommendation can be formulated for this topic, at this moment.

\section{b) Stapled hemorrhoidopexy (Longo procedure)}

Statement 5.10 : Stapled hemorrhoidopexy is associated with less pain and faster recovery compared to $\mathrm{CH}$ but has a higher recurrence rate. Agreement $100 \%$. Grade A.

\section{II) Technique}

Stapled hemorrhoidopexy ( $\mathrm{SH})$ uses a circular stapler to perform a circumferential rectal mucosectomy (excision of a doughnut of mucosa) immediately above the hemorrhoidal complex which results in disruption of the blood supply to the plexus, reducing engorgement, and resulting in a lifting of the anorectal mucosa which restores the normal anatomy of the anal canal, reducing any prolapse and enabling the hemorrhoidal cushions to perform their role in continence.

\section{III) Results}

Stapled hemorrhoidopexy is associated with less operating time, earlier return of bowel function, shorter hospital stay, less pain, faster functional recovery, shorter time off work and better wound healing compared to conventional hemorrhoidectomy (101). Meta-analyses looking at long-term outcomes after stapled hemorrhoidopexy and conventional hemorrhoidectomy found higher recurrence rates following hemorrhoidopexy (102). Quality of life was significantly better in the conventional group after 2-year follow up. The cost of the stapled hemorrhoidopexy procedure was significantly higher. In an RCT and systematic review, stapled hemorrhoidopexy is reported to be less painful compared with conventional hemorrhoidectomy $(101,103)$.

\section{IV) Complications}

Upto $10 \%$ of thepatients in thestapledhemorrhoidopexy group can experience some form of procedure-related event, and minor and major complications have been reported. The typical complaints of bleeding, discomfort and urinary retention are reported. However, potential complications may be serious: misplacement of the purse string suture may cause (severe) postoperative complications including rectovaginal fistulae, rectal perforation and retroperitoneal sepsis $(104,105)$. A unique syndrome of pain, urgency and tenesmus has been described and may respond to topical nifedipine (106).

c) Doppler-guided hemorrhoidal artery ligation (DGHAL)

Statement 5.11 : DGHAL is associated with less complications compared to $\mathrm{SH}$ and $\mathrm{CH}$. Agreement $85 \%$. Grade A.

Statement 5.12 : DGHAL has a significantly higher persistence/recurrence rate compared to SH. Agreement $92 \%$. Grade A.

Statement 5.13: Stapled hemorrhoidopexy and DGHAL are not recommended in case of grade 4 hemorrhoidal disease. Agreement 100\%. Grade B.

\section{I) Technique}

DGHAL technique uses a Doppler-equipped anoscope to identify and ligate the arteries supplying internal hemorrhoids. It is often accompanied by a mucosal plication which is called the recto-anal repair (RAR). Therefore, the technique is also referred to as DGHALRAR. These interventions correct both hemorrhoidal engorgement and bleeding (by progressive shrinkage of piles) and the prolapse (by scarring fixation). 


\section{II) Results}

DGHAL provides the theoretical advantage of less pain and enhanced recovery due to the absence of a surgical wound (as in conventional hemorrhoidectomy) or sutures above the dentate line (as in stapled hemorrhoidopexy). The meta-analysis of Simillis et al confirmed that hemorrhoidopexy and DGHAL are associated with less pain at least during the first 24 hours compared with open and closed hemorrhoidectomy. Postoperative pain score after DGHAL is lower than after SH (107). Lehur also found that DGHAL resulted in less pain than SH (108). Song could not show a difference in pain (109).

DGHAL resulted in less bleeding compared to open and stapled procedures and fewer reoperations than open, closed and Ligasure ${ }^{\circledR}$ procedures (102). Song confirmed that there was less bleeding and that the recurrence rate of DGHAL was higher on short term follow up but equal on long term follow up (109). Single center studies found that DGHAL was not inferior to conventional excisional hemorrhoidectomy for advanced disease in term of operative complications and long-term recurrence of symptoms $(110,111)$.

Higher recurrence rates are reported compared to surgical hemorrhoidectomies (open, closed, Ligasure ${ }^{\circledR}$ ) (102). The HubBLE trial compared DGHAL with RBL and concluded DGHAL is more effective for grade 2 and early grade 3 hemorrhoids at 1 year but significantly more expensive. DGHAL compared with a course of RBL was as effective (112).

DGHAL has a significantly higher persistence/ recurrence rate compared to $\mathrm{SH}(101,103,107)$. Lehur also concluded in a RCT that DGHAL had a higher recurrence rate, took longer and was more expensive (108). The meta-analysis of Song could not show a difference of long term recurrence, nor a difference in postoperative pain, operative time, hospital time, time before returning to work and reoperation rate (109). The meta-analysis, including one extra study, concluded the same, except that the total recurrence rate of DGHAL is higher than $\mathrm{SH}$ (113).

\section{III) Complications}

The same moderate complications of bleeding, discomfort, urinary retention, thrombosis and fissure formation are described as compared to other surgical interventions.

\section{d) Surgical therapies : conclusions}

While patients who underwent SH had less shortterm pain after 6 weeks, recurrence rates, symptoms, re-intervention rate and quality-of-life measures all favored conventional hemorrhoidectomy. In addition, $\mathrm{CH}$ is cheaper. As part of a tailored management plan for hemorrhoids, $\mathrm{CH}$ should be considered over $\mathrm{SH}$ as the surgical treatment of choice for hemorrhoids refractory to medical and instrumental treatment. SH and DGHAL are not recommended in grade 4 prolapse.

DHGAL and SH are associated with less postoperative pain and faster recovery, but higher recurrence rates. The advantages and disadvantages of each surgical treatment should be discussed with the patient before surgery to allow an informed decision to be made.

\section{Management of symptomatic external hemor- rhoids}

A thrombosed external hemorrhoid is easily recognized on physical examination as a usually tender blue lump at the anal verge, and no other workup or classification is needed. Most patients who present urgently (i.e. within $72 \mathrm{hrs}$ ) may benefit from incision or excision of the hemorrhoid and evacuation of the thrombus under local anesthesia $(114,115)$. Surgical excision of the involved pile is recommended in case of severe pain, necrosis or infection.

In the majority of cases however, spontaneous resolution of the thrombus can be expected, and conservative measures may suffice (short course of NSAID, stool softeners) albeit with a higher recurrence rate compared to incision or excision. The addition of topical nifedipine ointment was shown to accelerate resolution of the thrombosed hemorrhoids after 2 weeks of treatment (116).

\section{Specific conditions}

a) Pregnancy

Statement 6.1 : During pregnancy, conservative options are treatment of choice and hemorrhoidal disease should be reevaluated after delivery. Agreement 100\%. Grade C.

Statement 6.2 : Venotropics are probably safe during pregnancy, safety during lactation is unknown. Agreement 100\%. Grade C.

Statement 6.3 : IR coagulation should be avoided during pregnancy. Agreement 85\%. Grade B.

Statement 6.4: Pregnancy is an absolute contraindication for RBL. Agreement $92 \%$. Grade B.

Anorectal problems occur frequently during and after pregnancy, with up to $38 \%$ internal hemorrhoidal disease and up to $7.8 \%$ thrombosed external hemorrhoids by the third trimester $(117,118)$. Specific pregnancy-related risk factors include spontaneous vaginal delivery, birth weight greater than $3800 \mathrm{~g}$ and more than 20 minutes straining during childbirth (119). Constipation during pregnancy was found to be an important risk factor for development of hemorrhoidal and other anal disease (12). From a pragmatic point of view conservative options should be the treatment of choice during pregnancy, however there 
is currently insufficient data on safety of hemorrhoidal treatment during pregnancy.

Systemic therapy should be avoided during pregnancy and lactation, as safety of these treatments during pregnancy is not conclusive $(118,120)$. Sitz baths $(20$ g commercial salt in $40-50^{\circ} \mathrm{C}$ for 10 minutes 3 times per day) were found to be more efficient than rectal cream, however both options were already combined with psyllium fibers and glycerine suppositories (119). Local perianal support devices have been tested (121) but clinical trials are required.

Currently, no definite conclusion can be drawn with regard to the safety of venotropics during pregnancy and lactation. A cohort study in 2015, comparing pregnancy outcomes and newborn health between 8998 women exposed to venotropics during pregnancy and 27.963 unexposed women, showed no increased risk of adverse pregnancy outcome among exposed women (122). According to the Belgian guidelines of Cybele (www. cybele.be), the use of rutoside during pregnancy and lactation is probably safe. The use of MPFF is considered as probably safe during pregnancy but safety during lactation is unknown.

Infrared photocoagulation should be avoided during pregnancy, as a result of lack of studies on this item (expert opinion). In pregnancy, RBL is contra-indicated. If surgery is mandatory (necrosis of grade 4 hemorrhoids), closed hemorrhoidectomy has been performed safely during pregnancy (123).

\section{b) Inflammatory bowel disease (IBD)}

Statement 6.5 : IR coagulation should be avoided in active anorectal IBD. Agreement 100\%. Grade B.

Statement 6.6 : RBL should be avoided in active anorectal IBD. Agreement 100 \%. Grade B.

Statement 6.7: If there is clinical suspicion of IBD, this should be excluded before any type of proctological surgery. Agreement 100\%. Grade B.

Statement 6.8: If invasive therapy is needed for hemorrhoidal disease in IBD patients, it is advised to perform surgery during a quiescent phase of the disease. Agreement 100\%. Grade B.

Up to $20 \%$ of patients with IBD also suffer from hemorrhoids, although exact numbers are difficult to construe due to the complaints of underlying IBD (124).

In active anorectal inflammatory bowel disease, the use of infrared photocoagulation is strongly discouraged. Very few data are published about inflammatory bowel disease and RBL. Data from a small series of IBD patients in the seventies suggest that treating hemorrhoids is safe in patients with ulcerative colitis but not in Crohn's disease (125). More studies are required but currently, we advise not to treat internal hemorrhoids in active rectal disease.

The risk of severe complications after hemorrhoidectomy in IBD patients is higher than in patients without IBD. Within IBD, Crohn's disease holds a threefold higher risk of complications than ulcerative colitis $(17.1 \%$ vs. $5.5 \%)$. The highest risk of complications was found in patients not known to have IBD at the time of surgery. Therefore it is recommended to exclude IBD when there is clinical suspicion prior to any type of proctological surgery (124). Additionally it is recommended to perform surgery during a quiescent phase of the disease (36).

When carefully selected, patients with Crohn's disease may hold no increased risk of postoperative complications. Moreover, the complication rate was found to be lower than in the general population, possibly due to surgical bias with more meticulous operation techniques and hemostasis (126) .

\section{c) Post-radiation therapy}

Statement 6.9 : Due to potential complications, specific interventions to treat hemorrhoidal symptoms should be discouraged after pelvic irradiation, moreover because most of these symptoms are likely to be secondary to radiation proctopathy rather than hemorrhoids. Agreement $\mathbf{1 0 0 \%}$. Grade C.

In the absence of prospective studies, a survey on current management practice was conducted among surgeons. The majority of surgeons only treat the radiation proctopathy (formalin, APC) in case of coinciding hemorrhoids, although many surgeons use rubber band ligation, sclerotherapy and hemorrhoidectomy in these patients (127). However, even minor interventions on irradiated tissue can result in severe complications such as fistula and rectal stenosis. Recently, a small retrospective study on 52 patients over a period of 18 years showed no complications after 15 rubber band ligations and 2 hemorrhoidectomies in patients with radiation proctopathy (128).

Due to potential complications, specific interventions to treat hemorrhoidal symptoms should be discouraged after pelvic irradiation, moreover because most of these symptoms are likely to be secondary to radiation proctopathy rather than hemorrhoidal disease (129).

\section{d) $H I V$}

Statement 6.10 : There are no contra-indications for any type of treatment for symptomatic hemorrhoids in HIV-positive patients, depending on CD4 count. Agreement 92\%. Grade C.

In HIV-positive patients, hemorrhoids are as prevalent as in HIV-negative patients (respectively $49 \%$ vs. $48 \%$ ), however CD4+ T-cell count $<200 / \mu$ l was associated with 
lower prevalence of hemorrhoids ( $31 \%$ vs. $52 \%$ CD $4+>$ $200 / \mu 1)(130)$. In a small study, no difference in outcome of proctological surgery was observed in HIV-positive patients, irrespective of CD4+ T-cell count $(131,132)$.

In general, there are no contra-indications for treatment options for hemorrhoids in HIV-positive patients, although we do advise to take the CD4 count into account.

\section{e) Medication}

I) Anti-coagulants and anti-platelet agents

Statement 6.11: IR coagulation can be safely performed under aspirin and clopidogrel, in all other conditions of disturbed coagulation it should be used with caution. Agreement $61 \%$. Grade B.

Statement 6.12 : RBL should be avoided in patients on clopidogrel. Agreement $92 \%$. Grade B.

Statement 6.13 : RBL is contra-indicated in patients on oral anticoagulants. Agreement 85 \%. Grade B.

Statement 6.14 : Vitamine $\mathrm{K}$ antagonists should be stopped for 7 days, NOACs for 2 days and antiplatelet agents for 5 days before both office-based and surgical interventions. Agreement $85 \%$. Grade B.

Statement 6.15: Ideally anticoagulants should be restarted 2 weeks after RBL because of an unpredictable risk of bleeding. After hemorrhoidal surgery anticoagulants can be restarted immediately because hemostatic measures are taken during the operation. Agreement 100 \%. Grade.

Statement 6.16 : If hemorrhoid treatment is needed under anticoagulant therapy, a one-stage treatment should be considered (surgery). Agreement $85 \%$. Grade B.

Hemorrhoidal bleeding can be life-threatening in patients on anti-platelets agents/anti-coagulants, mostly in combination with constipation or fecal impaction (133). Infrared photocoagulation can be safely performed in patients under aspirin and clopidogrel. In all other conditions of disturbed coagulation (drug-induced, pathology), infrared photocoagulation should be used with caution because of risk of severe bleeding.

Bleeding after rubber band ligation is more frequent in patients on aspirin or warfarin compared to patients not taking antithrombotic medication $(25 \%$ on warfarin vs. $7.5 \%$ on aspirin vs. $2.9 \%$ in controls) (134). Patients on clopidogrel are at higher risk (relative risk 10) (135) and therefore clopidogrel should be replaced by aspirin (136). However, a recent study showed no difference in bleeding after rubber band ligation with or without cessation of clopidogrel (137).

Bleeding risk after general proctological surgery is around 5\% and considered to be low, while hemorrhoidal surgery is considered to have a moderate risk of bleeding, even when taking Aspirin.

Therefore, aspirin should not be stopped prior to performing instrumental treatment of hemorrhoids, especially if it is prescribed in secondary prophylaxis (138). However, it is recommended to discontinue anticoagulants for 7 days and anti-platelet agents other than aspirin for 5 days before both office-based as in surgical interventions if the cardiovascular risk allows discontinuation, despite the fact that the different modalities were not studied separately $(135,139)$. Novel oral anticoagulants (NOACs) have not been studied yet, but by extrapolation they should be stopped for 48-72 hours prior to other invasive procedures. The most difficult issue is when to restart anti-platelet agents or anticoagulants. Ideally this is only done once the bleeding risk has weaned, which is at least 7 days and ideally 14 days following an invasive therapeutic procedure. The risk has to be balanced patient-per-patient.

DGHAL and Emborrhoid technique are alternative options without discontinuation of anti-coagulants or anti-platelet agents $(138,140)$.

If urgent therapy for symptomatic hemorrhoidal disease is necessary and washout of anticoagulant therapy is not possible, a one-step surgical approach is advised to minimize cumulative bleeding risk.

II) Immunosuppressive drugs

Statement 6.17 : In the immunocompromised patient RBL should be avoided. Agreement $100 \%$. Grade C.

Statement 6.18 : It is advised to postpone elective procedures (office-based or surgical) until the end of adjuvant chemotherapy or during a drug holiday in case of palliative chemotherapy. Agreement 100 $\%$. Grade D.

In general, no data on immunocompromised patients are available in literature. Indirectly, 2 studies looked at risks of hemorrhoidal management in transplanted patients.

A history of hemorrhoids prior to allogeneic hematopoietic stem cell transplantation was associated with a significantly higher risk of perianal infection after transplantation (hazard ratio 3.09) (141). Preventive treatment of hemorrhoids before transplantation is an option but needs to be explored in trials.

In renal transplant patients, hemorrhoids were more frequently found in patients with rapid weight gain and patients between 30 and 50 years. However, no outcome data on conservative versus surgical management was mentioned (142). 
In case of immune suppression infrared photocoagulation can be used since no septic complications were reported, although specific studies on infrared photocoagulation in immune suppression are not available.

$\mathrm{RBL}$ is discouraged. If inevitable, antibiotic prophylaxis should be administered before performing any intervention due to the risk of bacteraemia (21). Evidence based literature about this is lacking. Some authors suggest adequate colonic preparation with an enema in case of immune suppression (74).

No studies on treatment of hemorrhoids in patients with chemotherapy/immune therapy have been conducted. It is recommended to postpone elective procedures (officebased or surgical) until the end of adjuvant therapy or during a drug holiday in case of palliative chemotherapy.

\section{f) Liver cirrhosis}

\section{Statement 6.19: RBL can safely be performed in compensated liver cirrhosis (Child-Pugh A). Agree- ment $85 \%$. Grade C.}

Rubber band ligation is generally discouraged in patients with advanced cirrhosis (Child Pugh B or C) due to the risk of severe secondary bleeding following the procedure (21). However, in a prospective study including 500 patients that underwent RBL, this procedure proved to be safe in 16 patients with coagulation disorders due to liver cirrhosis (143).

\section{Conclusions}

The current guidelines were generated using a Delphi consensus process and include recommendations on the clinical evaluation and management of symptomatic hemorrhoids according to the grade of prolapse as summarized in figure 2. It remains crucial to discuss all possible treatment options and their advantages and disadvantages with the patient, and balance them with patients' expectations.

\section{References}

1. MULLEN P. M. Delph : myths and reality. J. Health Organ. Manag., 2003, 17(1) : 37-52.

2. BALSHEM H., HELFAND M., SCHUNEMANN H. J., OXMAN A. D., KUNZ R., BROZEK J. et al. GRADE guidelines : 3. Rating the quality of evidence. J. Clin. Epidemiol., 2011, 64(4) : 401-406.

3. SUN Z., MIGALY J. Review of Hemorrhoid Disease: Presentation and Management. Clin. Colon Rectal Surg., 2016, 29(1) : 22-29.

4. MARGETIS N. Pathophysiology of internal hemorrhoids. Ann. Gastroenterol., 2019, 32(3) : 264-272.

5. LESTAR B., PENNINCKX F., KERREMANS R. The composition of anal basal pressure. An in vivo and in vitro study in man. Int. J. Colorectal. Dis., 1989, 4(2) : 118-122.

6. NELSON R. L., ABCARIAN H., DAVIS F. G., PERSKY V. Prevalence of benign anorectal disease in a randomly selected population. Dis. Colon Rectum, 1995, 38(4) : 341-344.

7. HAAS P. A., HAAS G. P. The prevalence of hemorrhoids and chronic constipation. Gastroenterology, 1990, 99(6) : 1856-1857.

8. JOHANSON J. F., SONNENBERG A. The prevalence of hemorrhoids and chronic constipation. An epidemiologic study. Gastroenterology, 1990, 98(2) : 380-386.

9. RISS S., WEISER F. A., SCHWAMEIS K., RISS T., MITTLBOCK M., STEINER G. et al. The prevalence of hemorrhoids in adults. Int. J. Colorectal. Dis., 2012, 27(2) : 215-220.

10. PEERY A. F., SANDLER R. S., GALANKO J. A., BRESALIER R. S., FIGUEIREDO J. C., AHNEN D. J. et al. Risk Factors for Hemorrhoids on Screening Colonoscopy. PLoS One, 2015, 10(9) : e0139100.

11. BURKITT D. P. Varicose veins, deep vein thrombosis, and haemorrhoids : epidemiology and suggested aetiology. Br. Med. J., 1972, 2(5813) : 556-561.

12. FERDINANDE K., DORREMAN Y., ROELENS K., CEELEN W., DE LOOZE D. Anorectal symptoms during pregnancy and postpartum: a prospective cohort study. Colorectal Dis., 2018, 20(12) : 1109-1116.

13. LODER P. B., KAMM M. A., NICHOLLS R. J., PHILLIPS R. K. Haemorrhoids : pathology, pathophysiology and aetiology. Br. J. Surg., 1994, 81(7) : 946-954.

14. JOHANSON J. F., SONNENBERG A. Constipation is not a risk factor for hemorrhoids : a case-control study of potential etiological agents. Am. J. Gastroenterol., 1994, 89(11) : 1981-1986.

15. PIGOT F., SIPROUDHIS L., ALLAERT F. A. Risk factors associated with hemorrhoidal symptoms in specialized consultation. Gastroenterol. Clin. Biol., 2005, 29(12) : 1270-1274.

16. GOENKA M. K., KOCHHAR R., NAGI B., MEHTA S. K. Rectosigmoid varices and other mucosal changes in patients with portal hypertension. $A m$. J. Gastroenterol., 1991, 86(9) : 1185-1189.

17. ZAGRIADSKII E. A., BOGOMAZOVA. M., GOLOVKO E. B. Conservative Treatment of Hemorrhoids : Results of an Observational Multicenter Study. Adv. Ther., 2018, 35(11) : 1979-1992.

18. JACOBS D. Clinical practice. Hemorrhoids. N. Engl. J. Med., 2014, 371(10) : 944-951.

19. NEUGUT A. I., GARBOWSKI G. C., WAYE J. D., FORDE K. A., TREAT M. R., TSAI J. L. et al. Diagnostic yield of colorectal neoplasia with colonoscopy for abdominal pain, change in bowel habits, and rectal bleeding. Am. J. Gastroenterol., 1993, 88(8) : 1179-1183.

\section{Grade 1 Grade 2 Grade 3 Grade 4}

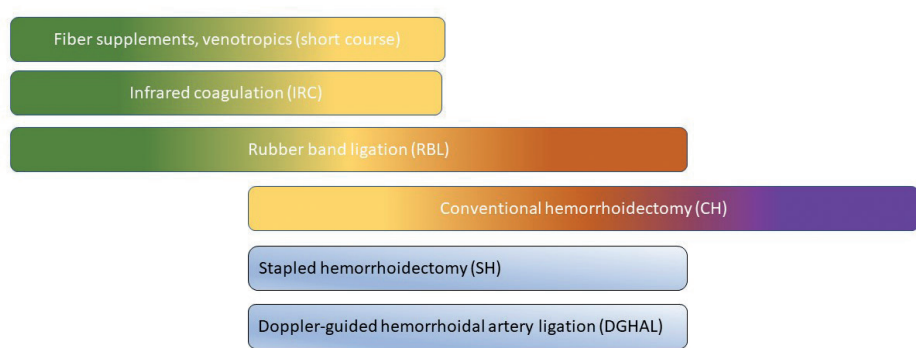

Figure 2. - Recommended current treatment options for hemorrhoidal disease according to the Goligher's classification. SH and DGHAL are colored differently of their inferior long-term result compared to $\mathrm{CH}$, but advantages and disadvantages of every technique should be discussed with each individual patient to choose the best treatment option. 
20. EPHARD E. A., RUTTER M. D., HAMILTON W. T. Clinical features of bowel disease in patients aged $<50$ years in primary care : a large case-control study. Br. J. Gen. Pract., 2017, 67(658) : e336-e344.

21. LOHSIRIWAT V. Hemorrhoids : from basic pathophysiology to clinical management. World J. Gastroenterol., 2012, 18(17) : 2009-2017.

22. RUBBINI M., ASCANELLI S. Classification and guidelines of hemorrhoidal disease : Present and future. World J. Gastrointest. Surg., 2019, 11(3) : 117121.

23. CLINICAL PRACTICE COMMITTEE A. G. A. American Gastroenterological Association medical position statement : Diagnosis and treatment of hemorrhoids. Gastroenterology, 2004, 126(5) : 1461-1462.

24. JC G. Surgery of the Anus, Rectum and Colon. Fourth edition edn. London; 1980

25. ALTOMARE D. F., RINALDI M., LA TORRE F., SCARDIGNO D., ROVERAN A., CANUTI S. et al. Red hot chili pepper and hemorrhoids the explosion of a myth: results of a prospective, randomized, placebocontrolled, crossover trial. Dis. Colon Rectum, 2006, 49(7) : 1018-1023.

26. ALONSO-COELLO P., MILLS E., HEELS-ANSDELL D., LOPEZYARTO M Z. Q., JOHANSON JF., GUYATT G. Fiber for the Treatment of Hemorrhoids Complications : a Systematic Review and Meta-Analysis. Am. J. Gastroenterol., 2006, 101(1) : 181-188.

27. ALONSO-COELLO P., GUYATT G., HEELS-ANSDELL D., JOHANSON J. F., LOPEZ-YARTO M., MILLS E. et al. Laxatives for the treatment of hemorrhoids. Cochrane Database Syst. Rev., 2005(4) : CD004649.

28. GARG P. Novel Nonsurgical Treatment of Intractable Bleeding in Hemorrhoid Patients on Anticoagulants. Surg. Innov., 2018, 25(4) : 423.

29. JACOBS D. O. Hemorrhoids: what are the options in 2018? Curr. Opin. Gastroenterol., 2018, 34(1) : 46-49.

30. BHARUCHA A. E., RAO S. S. An update on anorectal disorders for gastroenterologists. Gastroenterology, 2014, 146(1) : 37-45 e32.

31. COSMAN B. C. Piles of Money: "Hemorrhoids" Are a Billion-Dollar Industry. Am. J. Gastroenterol., 2019, 114(5) : 716-717.

32. LINARES-GIL M. J., VALLS J., HEREU-BOHER P., NEBOT F. J., DERAMON B., DIAZ-MUNIO E. et al. Topical Analgesia with Lidocaine Plus Diclofenac Decreases Pain in Benign Anorectal Surgery : Randomized, Double-blind, and Controlled Clinical Trial. Clin. Transl. Gastroenterol., 2018, 9(11) : 210

33. PERERA N., LIOLITSA D., IYPE S., CROXFORD A., YASSIN M., LANG P. et al. Phlebotonics for haemorrhoids. Cochrane Database Syst. Rev., 2012(8) : CD004322

34. ALONSO-COELLO P., ZHOU Q., MARTINEZ-ZAPATA M. J., MILLS E., HEELS-ANSDELL D., JOHANSON J. F. et al. Meta-analysis of flavonoids for the treatment of haemorrhoids. Br. J. Surg., 2006, 93(8) : 909-920.

35. AZIZ Z., HUIN W. K., BADRUL HISHAM M. D., TANG W. L., YAACOB S. Efficacy and tolerability of micronized purified flavonoid fractions (MPFF) for haemorrhoids: A systematic review and meta-analysis. Complement. Ther. Med., 2018, 39 : 49-55.

36. HIGUERO T., ABRAMOWITZ L., CASTINEL A., FATHALLAH N., HEMERY P., LACLOTTE DUHOUX C. et al. Guidelines for the treatment of hemorrhoids (short report). Journal of Visceral Surgery, 2016, 153(3): 213-218.

37. TEMPlETON J. L., SPENCE R. A., KENNEDY T. L., PARKS T. G., MACKENZIE G., HANNA W. A. Comparison of infrared coagulation and rubber band ligation for first and second degree haemorrhoids : a randomised prospective clinical trial. Br. Med. J. (Clin Res Ed), 1983, 286(6375) : 13871389.

38. AMBRose N. S., HARES M. M., ALEXANDER-WILLIAMS J., KEIGHLEY M. R. Prospective randomised comparison of photocoagulation and rubber band ligation in treatment of haemorrhoids. Br. Med J. (Clin Res Ed), 1983, 286(6375) : 1389-1391.

39. POEN A. C., FELT-BERSMA R. J., CUESTA M. A., DEVILle W., MEUWISSEN S. G. A randomized controlled trial of rubber band ligation versus infra-red coagulation in the treatment of internal haemorrhoids. Eur. J. Gastroenterol. Hepatol., 2000, 12(5) : 535-539.

40. GUPTA P. J. Infrared coagulation versus rubber band ligation in early stage hemorrhoids. Braz. J. Med. Biol. Res., 2003, 36(10) : 1433-1439.

41. MARQUES C. F., NAHAS S. C., NAHAS C. S., SOBRADO C. W., JR., HABR-GAMA A., KISS D. R. Early results of the treatment of internal hemorrhoid disease by infrared coagulation and elastic banding : a prospective randomized cross-over trial. Tech. Coloproctol., 2006, 10(4) : 312-317.

42. DIMITROULOPOULOS D., TSAMAKIDIS K., XINOPOULOS D., KARAITIANOS I., FOTOPOULOU A., PARASKEVAS E. Prospective, randomized, controlled, observer-blinded trial of combined infrared photocoagulation and micronized purified flavonoid fraction versus each alone for the treatment of hemorrhoidal disease. Clin. Ther., 2005, 27(6) : 746-754.

43. AHMAD A., KANT R., GUPTA A. Comparative Analysis of Doppler Guided Hemorrhoidal Artery Ligation (DG-HAL) \& Infrared Coagulation (IRC) in Management of Hemorrhoids. Indian J. Surg., 2013, 75(4) : 274-277.
44. WALKER A. J., LEICESTER R. J., NICHOLLS R. J., MANN C. V. A prospective study of infrared coagulation, injection and rubber band ligation in the treatment of haemorrhoids. Int. J. Colorectal. Dis., 1990, 5(2) : 113-116.

45. JOHANSON J. F., RIMM A. Optimal nonsurgical treatment of hemorrhoids : a comparative analysis of infrared coagulation, rubber band ligation, and injection sclerotherapy. Am. J. Gastroenterol., 1992, 87(11) : 1600-1606.

46. MACRAE H. M., MCLEOD R. S. Comparison of hemorrhoidal treatment modalities. A meta-analysis. Dis. Colon Rectum, 1995, 38(7) : 687-694.

47. SIM A. J., MURIE J. A., MACKENZIE I. Comparison of rubber band ligation and sclerosant injection for first and second degree haemorrhoids - a prospective clinical trial. Acta Chir. Scand., 1981, 147(8) : 717-720.

48. GARTELL P. C., SHERIDAN R. J., MCGINN F. P. Out-patient treatment of haemorrhoids : a randomized clinical trial to compare rubber band ligation with phenol injection. Br. J. Surg., 1985, 72(6) : 478-479.

49. KHAN N., MALIK M. A. Injection sclerotherapy versus electrocoagulation in the management outcome of early haemorrhoids. J. Pak. Med. Assoc., 2006, 56(12) : 579-582

50. YUKSEL B. C., ARMAGAN H., BERKEM H., YILDIZ Y., OZEL H., HENGIRMEN S. Conservative management of hemorrhoids : a comparison of venotonic flavonoid micronized purified flavonoid fraction (MPFF) and sclerotherapy. Surg. Today, 2008, 38(2) : 123-129.

51. PORRETT T. R., LUNNISS P. J. A prospective randomized trial of consultantled injection sclerotherapy compared with nurse practitioner-led noninvasive interventions in the management of patients with first and second degree haemorrhoids. Colorectal. Dis., 2001, 3(4) : 227-231.

52. ADAMI B., ECKARDT V. F., SUERMANN R. B., KARBACH U., EWE K. Bacteremia after proctoscopy and hemorrhoidal injection sclerotherapy. Dis. Colon Rectum, 1981, 24(5) : 373-374.

53. RIBBANS W. J., RADCLIFFE A. G. Retroperitoneal abscess following sclerotherapy for hemorrhoids. Dis. Colon Rectum, 1985, 28(3) : 188-189.

54. BULLOCK N. Impotence after sclerotherapy of haemorrhoids : case reports. $B M J, 1997$, 314(7078) : 419

55. BARWELL J., WATKINS R. M., LLOYD-DAVIES E., WILKINS D. C. Lifethreatening retroperitoneal sepsis after hemorrhoid injection sclerotherapy : report of a case. Dis. Colon Rectum, 1999, 42(3) : 421-423.

56. KAMAN L., AGGARWAL S., KUMAR R., BEHERAA., KATARIYA R. N. Necrotizing fascitis after injection sclerotherapy for hemorrhoids : report of a case. Dis. Colon Rectum, 1999, 42(3) : 419-420.

57. SUPPIAH A., PERRY E. P. Jaundice as a presentation of phenol induced hepatotoxocity following injection sclerotherapy for haemorrhoids. Surgeon, 2005, 3(1) : 43-44

58. RASHID M. M., MURTAZA B., GONDAL Z. I., MEHMOOD A., SHAH S. S., ABBASI M. H. et al. Injection sclerotherapy for haemorrhoids causing adult respiratory distress syndrome. J. Coll. Physicians Surg. Pak., 2006, 16(5) : 373-375.

59. ELRAM R., WASSERBERG N. Anorectal necrosis induced by injection sclerotherapy for hemorrhoids. Int. J. Colorectal. Dis., 2007, 22(8) : 997-998.

60. SCHULTE T., FANDRICH F., KAHLKE V. Life-threatening rectal necrosis after injection sclerotherapy for haemorrhoids. Int. J. Colorectal. Dis., 2008, 23(7) : 725-726

61. YANG P., WANG Y. J., LI F., SUN J. B. Hemorrhoid sclerotherapy with the complication of abdominal compartment syndrome : report of a case. Chin Med. J. (Engl), 2011, 124(12) : 1919-1920.

62. GUPTA N., KATOCH A., LAL P., HADKE N. S. Rectourethral fistula after injection sclerotherapy for haemorrhoids, a rare complication. Colorectal Dis., 2011, 13(1) : 105.

63. INDRASENA B., DORATIYAWA L. Fatal necrotizing fasciitis following sclerotherapy for haemorrhoids. Chin. Med. J. (Engl), 2013, 126(5) : 982 983.

64. TANWAR R., SINGH S. K., PAWAR D. S. Rectourethral fistula : A rare complication of injection sclerotherapy. Urol. Ann., 2014, 6(3) : 261-263.

65. FERNANDES V., FONSECA J. Polidocanol Foam Injected at High Doses with Intravenous Needle: The (Almost) Perfect Treatment of Symptomatic Internal Hemorrhoids. GE Port. J. Gastroenterol., 2019, 26(3) : 169-175.

66. BROWN S. R. Haemorrhoids : an update on management. Ther. Adv. Chronic Dis., 2017, 8(10) : 141-147

67. RAMZISHAM A. R., SAGAP I., NADESON S., ALI I. M., HASNI M. J. Prospective randomized clinical trial on suction elastic band ligator versus forceps ligator in the treatment of haemorrhoids. Asian J. Surg., 2005, 28(4) : 241-245.

68. CAZEMIER M., FELT-BERSMA R. J., CUESTA M. A., MULDER C. J. Elastic band ligation of hemorrhoids: flexible gastroscope or rigid proctoscope? World J. Gastroenterol., 2007, 13(4) : 585-587.

69. SCHLEINSTEIN H. P., AVERBACH M., AVERBACH P., CORREA P., POPOUTCHI P., ROSSINI L. G. B. Endoscopic Band Ligation for the Treatment of Hemorrhoidal Disease. Arq. Gastroenterol., 2019, 56(1) : 22-27.

70. GANZ R. A. The evaluation and treatment of hemorrhoids : a guide for the gastroenterologist. Clin. Gastroenterol. Hepatol., 2013, 11(6) : 593-603. 
71. WEHRMANN T., RIPHAUS A., FEINSTEIN J., STERGIOU N Hemorrhoidal elastic band ligation with flexible videoendoscopes: a prospective, randomized comparison with the conventional technique that uses rigid proctoscopes. Gastrointestinal Endoscopy, 2004, 60(2) : 191-195.

72. LEE H. H., SPENCER R. J., BEART R. W., JR. Multiple hemorrhoidal bandings in a single session. Dis. Colon Rectum, 1994, 37(1) : 37-41.

73. ALBUQUERQUE A. Rubber band ligation of hemorrhoids : A guide for complications. World J. Gastrointest. Surg., 2016, 8(9) : 614-620.

74. COCORULLO G., TUTINO R., FALCO N., LICARI L., ORLANDO G., FONTANA T. et al. The non-surgical management for hemorrhoidal disease. A systematic review. G. Chir., 2017, 38(1) : 5-14.

75. LINARES SANTIAGO E G. P. M., MENDOZA OLIVARES FJ, PELLICER BAUTISTA FJ, HERRERÍAS GUTIÉRREZ JM. Effectiveness of hemorrhoidal treatment by rubber band ligation and infrared photocoagulation. Esp. Entferm. Dig., 2001, $93: 238$

76. SHANMUGAM V., THAHA M. A., RABINDRANATH K. S., CAMPBELL K. L., STEELE R. J., LOUDON M. A. Rubber band ligation versus excisiona haemorrhoidectomy for haemorrhoids. Cochrane Database Syst. Rev., 2005(3) : CD005034.

77. COUGHLIN O. P., WRIGHT M. E., THORSON A. G., TERNENT C. A Hemorrhoid Banding : A Cost-Effectiveness Analysis. Dis. Colon Rectum, 2019, 62(9) : 1085-1094.

78. SCHÄFER H T. S., VIVALDI C : Radio frequency ablation (Rafaelo $\mathbb{R}$ procedure) for the treatment of prolapsing stage $\mathrm{III}^{\circ}$ hemorrhoids - technique and initial results. Coloproctology, 2018, $40: 204-210$.

79. DIDELOT J D. R. Radiofréquence hémorroïdaire : la nouvelle technique chirurgicale de choix pour le traitement des hémorroïdes internes? JFHOD meeting, 2019, CO.105.

80. ZAKHARCHENKO A., KAITOUKOV Y., VINNIK Y., TRADI F., SAPOVAL M., SIELEZNEFF I. et al. Safety and efficacy of superior rectal artery embolization with particles and metallic coils for the treatment of hemorrhoids (Emborrhoid technique). Diagn. Interv. Imaging, 2016, 97(11) 1079-1084.

81. FILINGERI V., ANGELICO R., BELLINI M. I., MANUELLI M., SFORZA D. Prospective randomised comparison of rubber band ligation (RBL) and combined hemorrhoidal radiocoagulation (CHR). Eur. Rev. Med. Pharmacol., Sci 2012, 16(2) : 224-229.

82. FILINGERI V., ANGELICO R., BELLINI M. I., MANUELLI M., SFORZA D. Ambulatory therapy with combined hemorrhoidal radiocoagulation. Eur. Rev. Med. Pharmacol. Sci., 2013, 17(1) : 130-133.

83. GUPTA P. J. Radiofrequency coagulation versus rubber band ligation in early hemorrhoids : pain versus gain. Medicina (Kaunas), 2004, 40(3) : 232-237.

84. GUPTA P. J. Radio-ablation of advanced grades of hemorrhoids with radiofrequency. Curr. Surg., 2003, 60(4) : 452-458.

85. GUPTA P. J. Novel technique : radiofrequency coagulation - a treatment alternative for early-stage hemorrhoids. Med. Gen. Med., 2002, 4(3) : 1 .

86. GUPTA P. J. Ambulatory hemorrhoid therapy with radiofrequency coagulation. Clinical practice paper. Rom. J. Gastroenterol., 2005, 14(1) : 37-41.

87. POSKUS T., DANYS D., MAKUNAITE G., MAINELIS A., MIKALAUSKAS S., POSKUS E. et al. Results of the double-blind randomized controlled trial comparing laser hemorrhoidoplasty with sutured mucopexy and excisional hemorrhoidectomy. Int. J. Colorectal. Dis., 2020, 35(3) : 481490.

88. NADERAN M., SHOAR S., NAZARI M., ELSAYED A., MAHMOODZADEH H., KHORGAMI Z. A Randomized Controlled Trial Com-paring Laser Intra-Hemorrhoidal Coagulation and Milligan-Morgan Hemorrhoidectomy. J. Invest. Surg., 2017, 30(5) : 325-331.

89. BRUSCIANO L., GAMBARDELLA C., TERRACCIANO G., GUALTIER G., SCHIANO DI VISCONTE M., TOLONE S. et al. Postoperative discomfort and pain in the management of hemorrhoidal disease: laser hemorrhoidoplasty, a minimal invasive treatment of symptomatic hemorrhoids. Updates Surg., 2019.

90. VIDAL V., LOUIS G., BARTOLI J. M., SIELEZNEFF I. Embolization of the hemorrhoidal arteries (the emborrhoid technique) : a new concept and challenge for interventional radiology. Diagn. Interv. Imaging, 2014, 95(3): 307-315.

91. VIDAL V., SAPOVAL M., SIELEZNEFF Y., DE PARADES V., TRADI F., LOUIS G. et al. Emborrhoid : a new concept for the treatment of hemorrhoids with arterial embolization : the first 14 cases. Cardiovasc. Intervent. Radiol., 2015, 38(1) : 72-78.

92. MOUSSA N., SIELEZNEFF I., SAPOVAL M., TRADI F., DEL GIUDICE C., FATHALLAH N. et al. Embolization of the superior rectal arteries for chronic bleeding due to haemorrhoidal disease. Colorectal Dis., 2017, 19(2) : 194-199.

93. TRADI F., LOUIS G., GIORGI R., MEGE D., BARTOLI J. M., SIELEZNEFF I. et al. Embolization of the Superior Rectal Arteries for Hemorrhoida Disease : Prospective Results in 25 Patients. J. Vasc. Interv. Radiol., 2018, 29(6) : 884-892 e881.
94. BHATTI M. I., SAJID M. S., BAIG M. K. Milligan-Morgan (Open) Versus Ferguson Haemorrhoidectomy (Closed) : A Systematic Review and MetaAnalysis of Published Randomized, Controlled Trials. World J. Surg., 2016, 40(6) : 1509-1519.

95. POKHAREL N., CHHETRI R. K., MALLA B., JOSHI H. N., SHRESTHA R. K. Haemorrhoidectomy: Ferguson's (closed) vs Milligan Morgan's technique (open). Nepal Med. Coll. J., 2009, 11(2) : 136-137.

96. MILITO G., GARGIANI M., CORTESE F. Randomised trial comparing LigaSure haemorrhoidectomy with the diathermy dissection operation. Tech. Coloproctol., 2002, 6(3) : 171-175.

97. NIENHUIJS S., DE HINGH I. Conventional versus LigaSure hemorrhoidectomy for patients with symptomatic Hemorrhoids. Cochrane Database Syst. Rev., 2009(1) : CD006761.

98. KENDIRCI M., SAHINER I. T., SAHINER Y., GUNEY G. Comparison of Effects of Vessel-Sealing Devices and Conventional Hemorrhoidectomy on Postoperative Pain and Quality of Life. Med. Sci. Monit., 2018, 24 : 21732179.

99. KWOK S. Y., CHUNG C. C., TSUI K. K., LI M. K. A doubleblind, randomized trial comparing Ligasure and Harmonic Scalpel hemorrhoidectomy. Dis. Colon Rectum, 2005, 48(2) : 344-348.

100. WANG J. Y., TSAI H. L., CHEN F. M., CHU K. S., CHAN H. M., HUANG C. J. et al. Prospective, randomized, controlled trial of Starion vs Ligasure hemorrhoidectomy for prolapsed hemorrhoids. Dis. Colon Rectum, 2007, 50(8) : 1146-1151.

101. WATSON A. J., COOK J., HUDSON J., KILONZO M., WOOD J., BRUHN H. et al. A pragmatic multicentre randomised controlled trial comparing stapled haemorrhoidopexy with traditional excisional surgery for haemorrhoidal disease : the eTHoS study. Health Technol. Assess., 2017, 21(70) : 1-224.

102. SIMILLIS C., THOUKIDIDOU S. N., SLESSER A. A., RASHEED S., TAN E., TEKKIS P. P. Systematic review and network meta-analysis comparing clinical outcomes and effectiveness of surgical treatments for haemorrhoids. Br. J. Surg., 2015, 102(13) : 1603-1618.

103. BURCH J., EPSTEIN D., SARI A. B., WEATHERLY H., JAYNE D., FOX D. et al. Stapled haemorrhoidopexy for the treatment of haemorrhoids : a systematic review. Colorectal Dis., 2009, 11(3) : 233-243; discussion 243.

104. FAUCHERON J. L., VOIRIN D., ABBA J. Rectal perforation with lifethreatening peritonitis following stapled haemorrhoidopexy. Br. J. Surg., 2012, 99(6) : 746-753.

105. GIANNINI I., FERRARA C., FIORE A., FALAGARIO U., DE FAZIO M., DI LENA M. et al. An original surgical approach to manage complete rectal lumen obliteration following stapled hemorrhoidopexy. Tech. Coloproctol., 2014, 18(7) : 661-663.

106. ASTERIA C. R., ROBERT-YAP J., ZUFFEREY G., COLPANI F., PASCARIELLO A., LUCCHINI G. et al. Tailored therapy for different presentations of chronic pain after stapled hemorrhoidopexy. Tech. Coloproctol., 2016, 20(5) : 299-307.

107. EMILE S. H., ELFEKI H., SAKR A., SHALABY M. Transanal hemorrhoidal dearterialization (THD) versus stapled hemorrhoidopexy (SH) in treatment of internal hemorrhoids : a systematic review and meta-analysis of randomized clinical trials. Int. J. Colorectal Dis., 2019, 34(1) : 1-11.

108. LEHUR P. A., DIDNEE A. S., FAUCHERON J. L., MEURETTE G., ZERBIB P., SIPROUDHIS L. et al. Cost-effectiveness of New Surgical Treatments for Hemorrhoidal Disease : A Multicentre Randomized Controlled Trial Comparing Transanal Doppler-guided Hemorrhoidal Artery Ligation With Mucopexy and Circular Stapled Hemorrhoidopexy. Ann. Surg., 2016, 264(5) : 710-716.

109. SONG Y., CHEN H., YANG F., ZENG Y., HE Y., HUANG H. Transanal hemorrhoidal dearterialization versus stapled hemorrhoidectomy in the treatment of hemorrhoids : A PRISMA-compliant updated meta-analysis of randomized control trials. Medicine (Baltimore), 2018, 97(29) : e11502.

110. TRENTI L., BIONDO S., GALVEZ A., BRAVO A., CABRERA J., KREISLER E. Distal Doppler-guided transanal hemorrhoidal dearterialization with mucopexy versus conventional hemorrhoidectomy for grade III and IV hemorrhoids : postoperative morbidity and long-term outcomes. Tech. Coloproctol, 2017, 21(5) : 337-344.

111. POPOV V., YONKOV A., ARABADZHIEVA E., ZHIVKOV E., BONEV S., BULANOV D. et al. Doppler-guided transanal hemorrhoidal dearterilization versus conventional hemorrhoidectomy for treatment of hemorrhoids - early and long-term postoperative results. BMC Surg., 2019, 19(1): 4 .

112. BROWN S., TIERNAN J., BIGGS K., HIND D., SHEPHARD N., BRADBURN M. et al: The HubBLe Trial : haemorrhoidal artery ligation (HAL) versus rubber band ligation (RBL) for symptomatic second- and third-degree haemorrhoids : a multicentre randomised controlled trial and health-economic evaluation. Health Technol. Assess., 2016, 20(88) : 1-150.

113. XU L., CHEN H., GU Y. Stapled Hemorrhoidectomy Versus Transanal Hemorrhoidal Dearterialization in the Treatment of Hemorrhoids: An 
Updated Meta-Analysis. Surg. Laparosc. Endosc. Percutan. Tech., 2019, 29(2) : 75-81.

114. GREENSPON J., WILLIAMS S. B., YOUNG H. A., ORKIN B. A. Thrombosed external hemorrhoids : outcome after conservative or surgical management. Dis. Colon Rectum, 2004, 47(9) : 1493-1498.

115. CHAN K. K., ARTHUR J. D. External haemorrhoidal thrombosis : evidence for current management. Tech. Coloproctol., 2013, 17(1) : 21-25.

116. PERROTTI P., ANTROPOLI C., MOLINO D., DE STEFANO G., ANTROPOLI M. Conservative treatment of acute thrombosed external hemorrhoids with topical nifedipine. Dis. Colon Rectum, 2001, 44(3) : 405409

117. AHLUND S., RADESTAD I., ZWEDBERG S., EDQVIST M., LINDGREN H. Haemorrhoids - A neglected problem faced by women after birth. Sex Reprod. Healthc., 2018, $18: 30-36$.

118. MIRHAIDARI S. J., PORTER J. A., SLEZAK F. A. Thrombosed external hemorrhoids in pregnancy: a retrospective review of outcomes. Int. J. Colorectal. Dis., 2016, 31(8) : 1557-1559.

119. SHIRAH B. H., SHIRAH H. A., FALlATA A. H., ALOBIDY S. N., HAWSAWI M. M. A. Hemorrhoids during pregnancy: Sitz bath vs. ano-rectal cream : A comparative prospective study of two conservative treatment protocols. Women Birth, 2018, 31(4) : e272-e277.

120. QUIJANO C. E., ABALOS E. Conservative management of symptomatic and/or complicated haemorrhoids in pregnancy and the puerperium. Cochrane Database Syst. Rev., 2005(3) : CD004077.

121. LIM S. S., YU C. W., AW L. D. Comparing topical hydrocortisone cream with Hai's Perianal Support in managing symptomatic hemorrhoids in pregnancy : a preliminary trial. J. Obstet. Gynaecol. Res., 2015, 41(2) : 238247.

122. LACROIX I., BEAU A. B., HURAULT-DELARUE C., BOUILHAC C., PETIOT D., VAYSSIERE C. et al. First epidemiological data for venotonics in pregnancy from the EFEMERIS database. Phlebology, 2016, 31(5) : 344348.

123. TROMPETTO M., CleRico G., COCORUllo G. F., GIORDANO P., MARINO F., MARTELLUCCI J. et al. Evaluation and management of hemorrhoids : Italian society of colorectal surgery (SICCR) consensus statement. Tech. Coloproctol., 2015, 19(10) : 567-575.

124. CRACCO N., ZINICOLA R. Is haemorrhoidectomy in inflammatory bowel disease harmful? An old dogma re-examined. Colorectal Dis., 2014, 16(7) : 516-519.

125. JEFFERY P. J., PARKS A. G., RITCHIE J. K. Treatment of haemorrhoids in patients with inflammatory bowel disease. Lancet, 1977, 1(8021) : 10841085.

126. D'UGO S. F.L., CADEDDU F., LECCESI L., DEL VECCHIO BLANCO G., CAlabrese E., Milito, G., DI LOREnZO, N., GASPARI A., SILERI, P. Medical and surgical treatment of haemorrhoids and anal fissure in Crohn's disease : a critical appraisal. BMC Gastroenterol., 2013, 13(47) : 13-47.

127. HAWKINS M., BILLINGHAM R., BASTAWROUS A. Hemorrhoid management in patients with radiation proctitis. Int. J. Colorectal. Dis., 2012, 27(12) : 1673-1677.

128. DE ROBLES M. S., YOUNG C. J. Rubber Band Ligation of Hemorrhoids is often a Necessary Complement in the Management of Hemorrhagic Radiation Proctitis. Scand. J. Surg., 2019 : 1457496918822619.

129. JONGEN J., KAHLKE V., PETERSEN S. Letter to the editor concerning :
Hawkins M, Billingham R, Bastawrous A. Hemorrhoid management in patients with radiation proctitis. Int. J. Colorectal. Dis., 2012 Jun 20. (Epub ahead of print). Int. J. Colorectal. Dis., 2013, 28(2) : 277.

130. PARVIN R., KOLLI S., SHAH J., JHAVERI M., REDDY M. Upper and Lower Gastrointestinal Endoscopic Findings in HIV-Infected Patients in the Era of Highly Active Antiretroviral Therapy. Gastroenterology Res., 2018, 11(2) : 95-99.

131. OH H. K., MOON S. H., RYOO S., CHOE E. K., PARK K. J. Results of surgical treatment on benign anal diseases in Korean HIV-positive patients. J. Korean Med. Sci., 2014, 29(9) : 1260-1265.

132. FAN Z., ZHANG Y. Treatment of Prolapsing Hemorrhoids in HIV-Infected Patients with Tissue-Selecting Technique. Gastroenterol. Res. Pract., 2017, 2017 : 1970985.

133. OZDIL B., AKKIZ H., SANDIKCI M., KECE C., COSAR A. Massive lower gastrointestinal hemorrhage secondary to rectal hemorrhoids in elderly patients receiving anticoagulant therapy : case series. Dig. Dis. Sci., 2010, 55(9) : 2693-2694.

134. IYER V. S., SHRIER I., GORDON P. H. Long-term outcome of rubber band ligation for symptomatic primary and recurrent internal hemorrhoids. Dis. Colon Rectum, 2004, 47(8) : 1364-1370.

135. NELSON R. S., EWING B. M., TERNENT C., SHASHIDHARAN M., BLATCHFORD G. J., THORSON A. G. Risk of late bleeding following hemorrhoidal banding in patients on antithrombotic prophylaxis. Am. J. Surg., 2008, 196(6) : 994-999; discussion 999.

136. PIGOT F., JUGUET F., BOUCHARD D., CASTINEL A. Do we have to stop anticoagulant and platelet-inhibitor treatments during proctological surgery? Colorectal. Dis., 2012, 14(12) : 1516-1520.

137. HITE N., KLINGER A. L., MILLER P., BECK D. E., WHITLOW C. B., HICKS T. C. et al. Clopidogrel bisulfate (Plavix) does not increase bleeding complications in patients undergoing rubber band ligation for symptomatic hemorrhoids. J. Surg. Res., 2018, $229:$ 230-233.

138. VENTURINI M., DE NARDI P., MARRA P., PANZERI M., BREMBILLA G., MORELLI F. et al. Embolization of superior rectal arteries for transfusion dependent haemorrhoidal bleeding in severely cardiopathic patients : a new field of application of the "emborrhoid" technique. Tech. Coloproctol., 2018, 22(6) : 453-455.

139. NELSON R. S., THORSON A. G. Risk of bleeding following hemorrhoidal banding in patients on antithrombotic therapy. Gastroenterol. Clin. Biol., 2009, 33(6-7) : 463-465.

140. ATALLAH S., MAHARAJA G. K., MARTIN-PEREZ B., BURKE J. P., ALBERT M. R., LARACH S. W. Transanal hemorrhoidal dearterialization (THD) : a safe procedure for the anticoagulated patient? Tech. Coloproctol., 2016, 20(7) : 461-466.

141. MO X. D., YAN X., HU W., ZHANG X. H., XU L. P., WANG Y. et al : Perianal Infections in the Phase before Engraftment after Allogeneic Hematopoietic Stem Cell Transplantations : A Study of the Incidence, Risk Factors, and Clinical Outcomes. Acta Haematol., 2018, 139(1) : 19-27.

142. TALlarita T., GURRIERI C., CAPPELlANI A., CORONA D., GAGLIANO M., GIUFFRIDA G. et al. Clinical features of hemorrhoidal disease in renal transplant recipients. Transplant. Proc., 2010, 42(4) : 11711173 .

143. KOMBOROZOS V. A., SKREKAS G. J., PISSIOTIS C. A. Rubber band ligation of symptomatic internal hemorrhoids : results of 500 cases. Dig. Surg., 2000, 17(1) : 71-76. 